\title{
Land-based climate change mitigation measures can affect agricultural markets and food security
}

\author{
Shinichiro Fujimori ${ }^{1,2,3,13 凶}$, Wenchao Wu ${ }^{4,13 \bowtie}$, Jonathan Doelman ${ }^{5,6}$, Stefan Frank ${ }^{3}$, \\ Jordan Hristov $\mathbb{1}^{7}$, Page Kyle ${ }^{8}$, Ronald Sands $\mathbb{1}^{9}$, Willem-Jan van Zeist ${ }^{10}{ }^{10}$, Petr Havlik $\mathbb{1}^{3}$, \\ Ignacio Pérez Domínguez $\mathbb{(}^{7}$, Amarendra Sahoo ${ }^{7}$, Elke Stehfest $\mathbb{C}^{5}$, Andrzej Tabeau ${ }^{10}$, Hugo Valin $\mathbb{D}^{3}$, \\ Hans van Meij|10,11, Tomoko Hasegawa ${ }^{2,12}$ and Kiyoshi Takahashi ${ }^{2}$
}

\begin{abstract}
Earlier studies have noted potential adverse impacts of land-related emissions mitigation strategies on food security, particularly due to food price increases-but without distinguishing these strategies' individual effects under different conditions. Using six global agroeconomic models, we show the extent to which three factors-non- $\mathrm{CO}_{2}$ emissions reduction, bioenergy production and afforestation-may change food security and agricultural market conditions under $2^{\circ} \mathrm{C}$ climate-stabilization scenarios. Results show that afforestation (often simulated in the models by imposing carbon prices on land carbon stocks) could have a large impact on food security relative to non- $\mathrm{CO}_{2}$ emissions policies (generally implemented as emissions taxes). Respectively, these measures put an additional 41.9 million and 26.7 million people at risk of hunger in 2050 compared with the current trend scenario baseline. This highlights the need for better coordination in emissions reduction and agricultural market management policies as well as better representation of land use and associated greenhouse gas emissions in modelling.
\end{abstract}

$\mathrm{n}$ meeting near- and long-term climate change mitigation goals (for example, the Paris Agreement), the energy sector accounts for the majority of greenhouse gas (GHG) emissions in most nations and is thus the target of most present-day emissions mitigation policies. However, agriculture, forestry and other land use (AFOLU) account for 20-25\% of global GHG emissions in $2010^{1}$ and cannot be ignored in the context of meeting ambitious long-term climate change mitigation targets. Both the magnitude of baseline emissions and the relative lack of available technologies to eliminate these emissions make AFOLU emissions especially important in the context of climate change mitigation. This is in contrast to the energy sector, which can see its emissions become net zero or even net negative if carbon-removal technologies are used ${ }^{2}$.

The future emissions reduction potential in the AFOLU sector has been characterized in the literature as having relatively large emission reductions available at low cost compared with other sectors ${ }^{3-5}$. However, the emissions reduction potentials are understood to be limited, with full (100\%) removal not possible regardless of effort in many cases ${ }^{6}$. Moreover, Hasegawa et al. highlighted remarkable food security concerns associated with the inclusion of AFOLU in climate change mitigation actions ${ }^{7}$; they also compared the impacts of climate change and its mitigation on agricultural production and concluded that the latter would be larger ${ }^{7}$. Although such impacts are understood to be heterogeneous within any population (for example, low-income consumers are less able to withstand agricultural commodity price shocks), regional averages are nevertheless useful for comparing scenario outcomes. The present study contributes to this discussion by starting with the observation that there are three main channels by which AFOLU-focused climate change mitigation policies may exacerbate food insecurity. One is promotion of large-scale bioenergy crop expansion; low-emissions scenarios in integrated assessment models (IAMs) have highlighted the potential importance of bioenergy, particularly bioenergy with carbon capture and storage (BECCS), for reducing costs and enabling deep system-wide emissions mitigation ${ }^{8-10}$. The consequent competition between food and bioenergy production can cause increased prices and reduced supplies of food crop commodities. Second, policies that price or constrain non- $\mathrm{CO}_{2}$ emissions from agricultural production can directly increase costs of food production and thus food commodity prices ${ }^{11,12}$. The third channel is afforestation policies, which incentivize a reduction in cropland and pastureland supply.

While these secondary impacts of AFOLU emissions mitigation have been addressed in the literature ${ }^{13,14}$, and one such study proposes inclusive policy designs to prevent adverse side effects, the present body of knowledge has not identified the relative importance of the factors that drive potential food security risk in a single consistent analytical framework. Studies have focused on each element individually; for example, the direct impacts of non- $\mathrm{CO}_{2}$ emissions reductions ${ }^{15}$ or the implications of bioenergy expansion ${ }^{12}$. Afforestation has also been addressed individually, albeit for carbon sequestration potential ${ }^{16,17}$. Some studies have examined the degree of potential carbon sequestration of afforestation and the costs thereof and have warned that food insecurity may result from forest carbon sequestration ${ }^{18,19}$. A remarkable study ${ }^{20}$ incorporated

Department of Environmental Engineering, Kyoto University, Kyoto, Japan. ${ }^{2}$ Center for Social and Environmental Systems Research, National Institute for Environmental Studies (NIES), Tsukuba, Japan. ${ }^{3}$ International Institute for Applied Systems Analysis (IIASA), Laxenburg, Austria. ${ }^{4}$ Social Sciences Division, Japan International Research Center for Agricultural Sciences (JIRCAS), Tsukuba, Japan. ${ }^{5}$ PBL Netherlands Environmental Assessment Agency, The Hague, the Netherlands. ${ }^{6}$ Copernicus Institute for Sustainable Development, Utrecht University, Utrecht, the Netherlands. ${ }^{7}$ European Commission, Joint Research Center, Seville, Spain. ${ }^{8}$ Joint Global Change Research Institute, Pacific Northwest National Laboratory, College Park, MD, USA. ${ }^{9}$ Economic Research Service, US Department of Agriculture, Washington, DC, USA. ${ }^{10}$ Wageningen Economic Research, Wageningen University and Research, The Hague, the Netherlands. "'Agricultural Economics and Rural Policy Group, Wageningen University, Wageningen, the Netherlands. ${ }^{12}$ College of Science and Engineering, Ritsumeikan University, Kusatsu, Japan. ${ }^{13}$ These authors contributed equally: Shinichiro Fujimori, Wenchao Wu. 凶e-mail: fujimori.shinichiro.8a@kyoto-u.ac.jp; wuwenchao@affrc.go.jp 
$\begin{array}{lll}\text { Primary factors } & \text { Primary factors } & \text { Secondary factors }\end{array}$

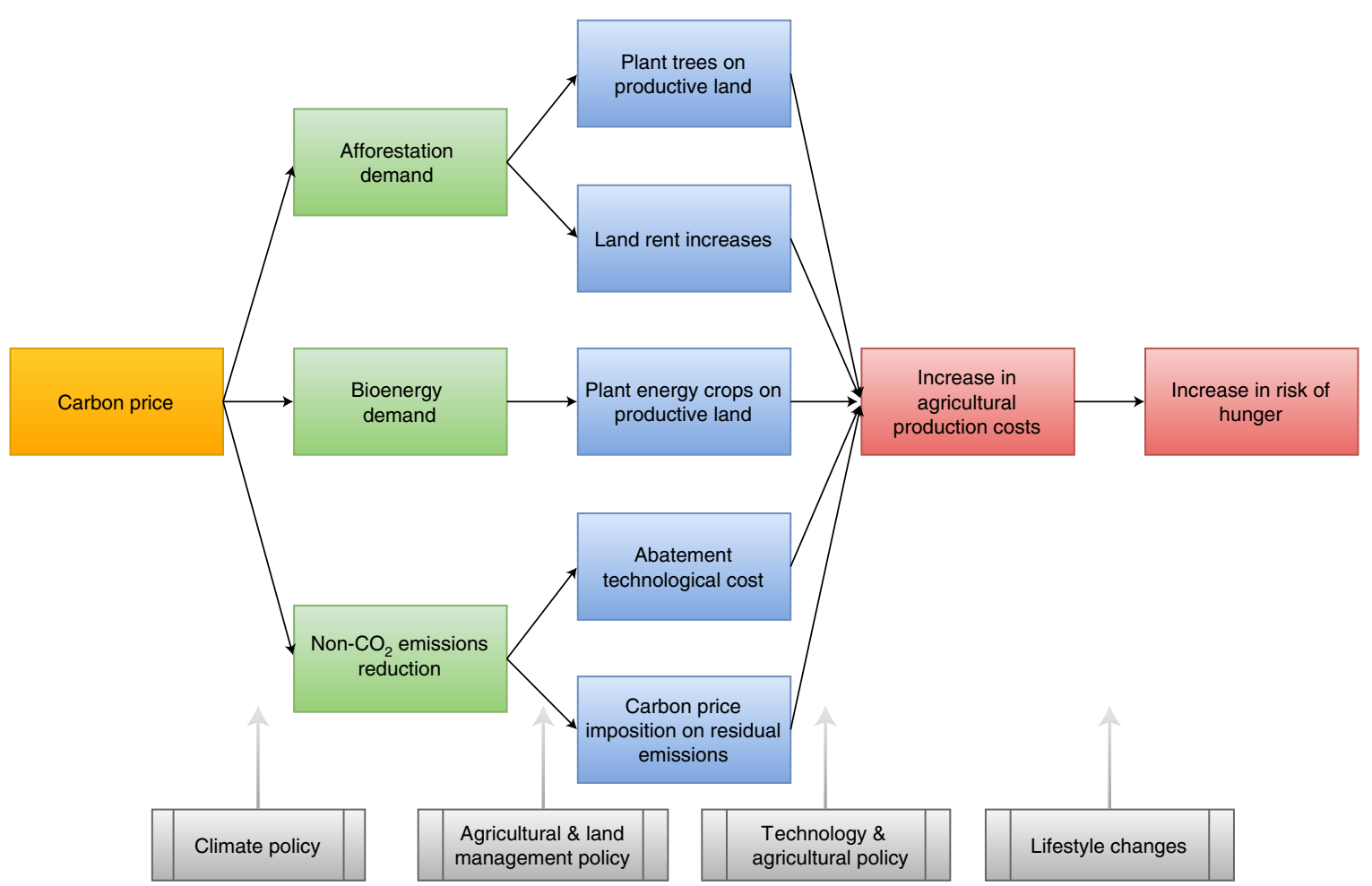

Fig. 1 | Representation of climate change mitigation measures and their potential effects on agricultural prices and the risk of hunger. The three measures considered-namely afforestation, bioenergy and non- $\mathrm{CO}_{2}$ emissions reduction-are shown in the green boxes and can be decomposed into secondary factors (blue boxes). These can affect agricultural production costs, which in turn might affect food security. Sectoral policies and lifestyle changes (grey arrows at the bottom) can be targeted at different elements of the figure.

these three factors and climate change impacts on yield but did not consider the stringent climate policy in line with the Paris Agreement, which aims to limit the global mean temperature increase to below $2{ }^{\circ} \mathrm{C}$ over pre-industrial levels, and limited physical indicators such as emissions, bioenergy, land use and the number of people at risk of hunger are reported.

Here we show the relative extent to which energy crop expansion, non- $\mathrm{CO}_{2}$ emissions reduction in the agricultural sector and afforestation affect agricultural markets and food security under climate mitigation scenarios. Understanding the potential risk of food insecurity associated with these three GHG emissions abatement strategies is key to the design of policies that reduce emissions while minimizing unintended adverse consequences. To analyse each cause individually, we examine several scenarios that are consistent with limiting the global mean temperature increase to below $2{ }^{\circ} \mathrm{C}$. Figure 1 summarizes the logical chains of the causes and effects of climate change mitigation measures on risk of hunger and agricultural price increases as adopted in this study-and discussed in greater detail later. To investigate the uncertainty range, this study employ six global agroeconomic models representing agriculture and land-use systems and their emissions-namely AIM/ $\mathrm{Hub}^{21}$, CAPRI $^{22}$, FARM $^{23}$, GCAM ${ }^{24}$, GLOBIOM $^{25}$ and MAGNET-IMAGE ${ }^{26}$. For the scenarios, the carbon prices, bioenergy production requirements and forested land area are harmonized where possible among the models. AIM/Hub, FARM and GCAM represent the land-use and energy systems explicitly; therefore, afforestation and the bioenergy land requirement are endogenously determined in response to carbon prices. Other models use exogenous parameters to achieve the scenarios' specifications. We found that the models' representations of non- $\mathrm{CO}_{2}$ emissions pricing were generally consistent, whereas the implementation of afforestation-related policies varied from one model to the next. We also employ a 'hunger measurement tool' which encompasses average calorie consumption per person, minimum calorific requirement and the coefficient of variation $(\mathrm{CV})$ of the food-consumption distribution within countries. This enables us to explore the number of people at risk of hunger ${ }^{7,27,28}$. For comparison, we also ran baseline scenarios that excluded new climate policies to extend the historical trend, including land management or regulation. Further scenario assumptions can be found in Methods. The scenarios analysed in this study assume the socioeconomic background of Shared Socioeconomic Pathways (SSP) 2 (refs. ${ }^{29,30}$ ), and for the climate policy scenarios, representative concentration pathway (RCP) 2.6 equivalent carbon prices are applied, which are taken from the SSP database. To explore the socioeconomic uncertainty, we have also examined scenarios under SSP1 ('Sustainability') and SSP3 ('Regional Rivalry'). See Methods for more details and illustration of the overall research framework (Supplementary Fig. 1). Note that climate change impacts are not taken into account in this scenario framework; therefore, uncertainty associated with the state of the climate (that is, RCPs) and climate models assessed in previous studies $^{7}$ are beyond the scope of this study. Neither do we consider climate variability, which has been discussed in the literature, but these should be carefully considered as recent literature reports ${ }^{31}$.

\section{Results}

Main indicators. In the baseline scenarios, global average calorie availability over the upcoming decades continuously increases, mainly due to income growth in developing countries, which drives food demand, reaching $3,058 \mathrm{kcal}$ per person per day in 2050 $(2,996-3,260 \mathrm{kcal}$ among the models; hereafter, ranges indicate 


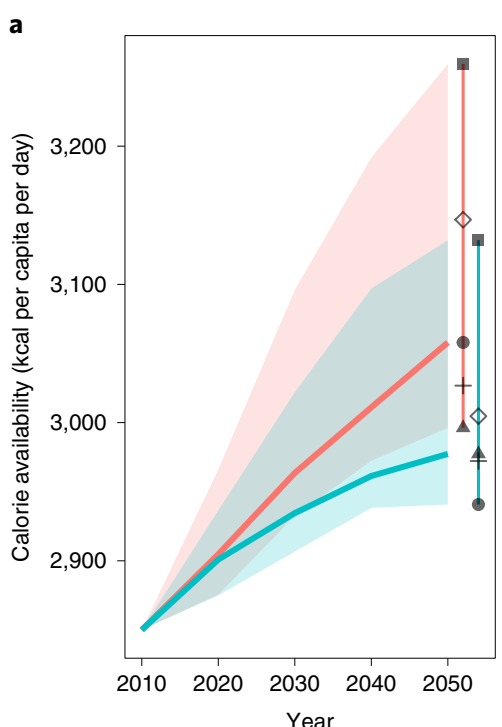

d

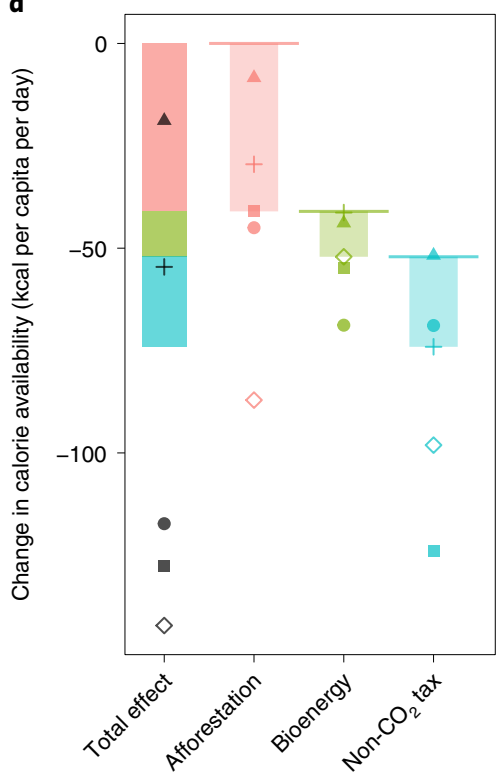

b

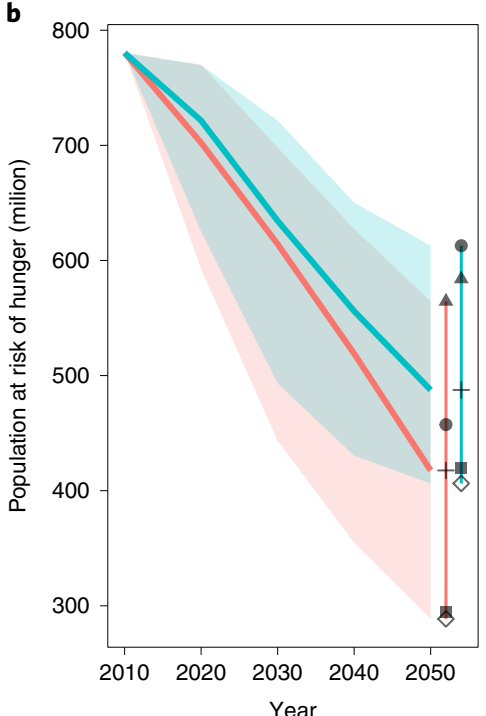

e

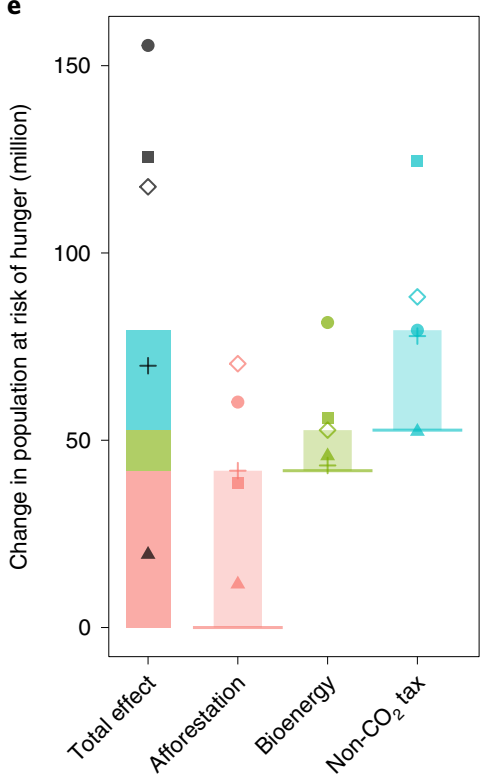

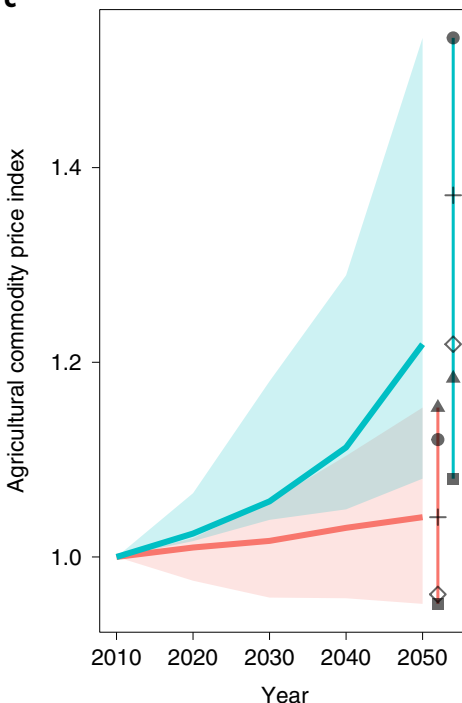

f

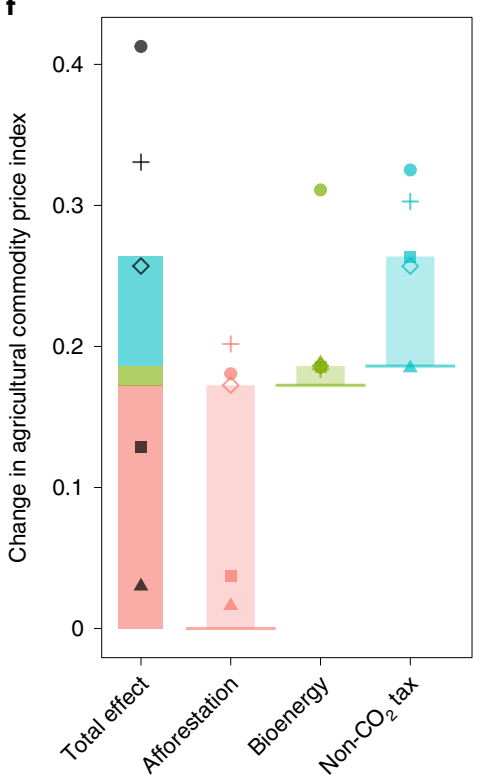

Climate policy

- Baseline

- Full mitigation

Model

- AIM/Hub

- farm

+ GCAM

- GLOBIOM

$\diamond$ MAGNET-IMAGE

Component

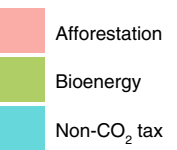

Fig. 2 Decomposition of three factors. a-c, Calorie availability (a), population at risk of hunger (b) and agricultural commodity price (c) in baseline and mitigation (full) scenarios. The shaded areas and makers in panels a-c show model uncertainty ranges and individual model results, respectively. $\mathbf{d}-\mathbf{f}$, The effects of each land-based mitigation measure on the variation of these three indicators is shown for SSP2. This figure's results are based on five models with complete scenarios and six models, as shown in Supplementary Fig. 4.

the inter-model spread; Fig. 2a). Accordingly, the number of people at risk of hunger declines overtime, to 417.6 million (288.6 million-564.4 million) in 2050 (Fig. 2b). This trend is consistent with the earlier studies ${ }^{7,13,32}$. The models' general agricultural producer price indices are projected to be almost constant over this time frame, with a range of 0.95 to 1.15 in 2050 (Fig. 2c). A similar degree of inter-model variation in projected prices has been observed in earlier studies as well ${ }^{33}$. Agricultural demand increases and technological improvement are the main upward and downward drivers of prices, respectively, which tend to offset each other. Crop production, livestock production, food consumption, agricultural price, cropland and pastureland information can be found in the Supplementary Information.

Under the climate change mitigation scenario to attain well below $2{ }^{\circ} \mathrm{C}$ global mean temperature, we implemented carbon (or GHG) pricing, although not all of the models in the study have explicit representations of such pricing, so the exact implementation of this policy is model-specific (Supplementary Fig. 2). A previous model comparison capped the carbon price for AFOLU emissions at US\$200 $\mathrm{t}^{-1} \mathrm{CO}_{2}$-equivalent $\left(\mathrm{CO}_{2} \mathrm{e}\right)$ (ref. ${ }^{13}$ ); however, because carbon prices are not expected to exceed that level by 2050, we did not apply such a cap in this study. Along with the carbon emissions price imposition (that is, carbon tax), GHG emissions mitigation actions are carried out by the agricultural and land-use system, pushing up the production cost, land rent and agricultural commodity producer prices (Fig. 2c). Consequently, calorie availability decreases by 117 (19-142) kcal per capita per day, and the population at risk of hunger increases by 117.7 (19.5-155.4) million in 2050, and that increases over the period (Fig. 2a,b). For most indicators, climate change mitigation policy impacts increased as the level of climate change mitigation strengthened over time (49.8 (3.5-99.4) million in 2030). 
Shifting to the decomposition analysis, the population at risk of hunger in 2050 increases by 41.9 million due to afforestation, 10.8 million from bioenergy production and 26.7 million from non- $\mathrm{CO}_{2}$ emissions abatement (Fig. 1e; numbers are multi-model medians). These can be mostly explained by average food consumption decrease (Fig. 2d) as a consequence of agricultural commodity price increases (Fig. 2f). For example, afforestation, bioenergy and non- $\mathrm{CO}_{2}$ emissions induce agricultural price increases by $17.2 \%$, $1.4 \%$ and $7.8 \%$, respectively (numbers are multi-model medians of a volume-weighted composite agricultural commodity that includes all crop and livestock products). Whereas the median shows the relative magnitudes of the three individual causes, the uncertainty can be assessed in the inter-model variability. The impact of modelled afforestation policies on additional risk of hunger ranges from 11.6 million to 70.4 million persons. These model variations would depend on the representation of the mitigation measures and model structure which are discussed in detail later. Given that there is model uncertainty, we carried out a sensitivity analysis to test whether a specific 'extreme' model would lead to this conclusion. This sensitivity analysis is conducted by withdrawing one model and iterating for all models. The conclusion is that our results are not dependent on a specific model (Supplementary Fig. 3). Also, analysis based on all models with complete sets of scenarios show similar patterns (Supplementary Fig. 4).

Note that models which include explicit energy and economic components show non-agricultural and non-land use related effects to some extent (for example, income loss associated with low-carbon energy technologies). It would be smaller than others except for AIM/Hub, which shows 29.0 million additional people becoming at risk of hunger (Supplementary Fig. 5).

Drivers of food price increases. Afforestation for the purpose of sequestering carbon from the atmosphere to the terrestrial system is incentivized by economically valuing terrestrial carbon above and belowground. Total $\mathrm{CO}_{2}$ emissions drastically decrease in the mitigation scenarios (Fig. 3a), becoming negative by 2050 in most of the scenarios (median: $-3.80 \mathrm{GtCO}_{2}$; from $-0.24 \mathrm{GtCO}_{2}$ to $-13.74 \mathrm{Gt}_{\mathrm{CO}_{2}}$ ). Accordingly, forested area increases by $11.1 \%$ (17.5-24.7\%) in 2050 relative to baseline scenarios, and these expansions put additional pressure on the agricultural sector (Fig. 3e). Land rent (average land rent among land-use sectors) can also increase due to land carbon sink prices; both factors would increase the average land rent by $67 \%, 172 \%$ and $366 \%$ in 2050 relative to the baseline scenarios in GCAM, MAGNET-IMAGE and AIM/Hub models, respectively. The pastureland also decreases accordingly (Supplementary Fig. 6).

Non- $\mathrm{CO}_{2}$ emissions mitigation is the second-largest contributor to the price increases associated with mitigation measures. There are basically two factors to increase the agricultural production prices. First, $\mathrm{CH}_{4}$ and $\mathrm{N}_{2} \mathrm{O}$ emissions abatement technologies are implemented endogenously, which directly increases the agricultural production costs, particularly in livestock products (Supplementary Fig. 7). Second, where $\mathrm{CO}_{2}$ emissions can attain negative values if $\mathrm{CO}_{2}$-removal technologies are applied, non- $\mathrm{CO}_{2}$ emissions cannot become negative and do not approach zero in the scenarios; residual emissions remain at $74.5 \%$ (56.5-87.8\%) of baseline emissions (Fig. $3 \mathrm{~b}, \mathrm{c})$. These values are slightly greater than existing literature but probably due to the sectoral coverage differences because the literature also includes non-agricultural related emissions ${ }^{34,35}$. These remaining emissions are subject to the carbon price, increasing the costs of crop and animal commodity production. Interestingly, these relatively modest non- $\mathrm{CO}_{2}$ emissions reductions in the agricultural sector imply large reductions in the energy system at these carbon prices (Fig. 3h).

Finally, the bioenergy crops can compete with food crops for cropland, putting upward pressure on land rents and thus agricultural commodity prices. Current model estimates show the bioenergy cropland area is 185 (61-494) million ha in 2050 under the full mitigation policy, which accounts for $11 \%$ of present-day total cropland area (Fig. 3d).

Although afforestation and bioenergy both need large amounts of land and therefore might compete with land for food production, results suggest that the effect of afforestation is larger than bioenergy. This is because afforestation requires more land than bioenergy in the scenarios, which is probably due to differences in long-term emissions mitigation potential per unit land area, particularly when the bioenergy crop commodities are used with carbon capture and storage for negative-emissions final energy production. In the bioenergy scenario, bioenergy land increase by 109 (56-690) million ha in 2050, along with even a small increase of cropland (the median change is +23 million ha, with a range from -59 million ha to +86 million ha); whereas in the afforestation scenario, forest area increases by 420 (74-895) million ha, with the decrease of cropland by 103 (39-148) million ha. Further, while the amount of cropland allocated to bioenergy production is determined by the bioenergy commodity demands of the energy system, the amount of land dedicated to afforestation has no practical limit ${ }^{36}$. In terms of characterizing the inter-model variability, it would be worthwhile to understand the contribution of the different models' structures and assumptions to the consequent reported results. Four models reported in Fig. 3 use land-nesting representations-either logit or CET functions (AIM/Hub, FARM, GCAM and MAGNETIMAGE) - of which three are CGE models (AIM/Hub, FARM and MAGNET-IMAGE). However, even models of a similar structural type have quite different results in this study, suggesting that other factors such as the parameterization of the land allocation decisions are stronger drivers of the inter-model variability. For example, AIM/Hub and GCAM use relatively flexible parameters for competition between cropland and forest, whereas MAGNET-IMAGE has less flexibility (Supplementary Table 1). Moreover, the biofuel representation varies among models as Supplementary Table 1 indicates. Practically, it would be difficult to fully harmonize it owing to the diversity of the model types and characteristics, which should be taken into account when interpreting the results.

The above-mentioned three drivers are also compatible with the carbon prices that clearly show the correlation, while there are some inter-model variations in the carbon-price assumptions (Fig. 3g-i). Food consumption, agricultural prices and risk of hunger similarly show the clear responses to carbon prices (Supplementary Fig. 8). However, looking at the emissions reduction over the food-consumption changes, the models' dependency is remarkable, and for example, GLOBIOM shows relatively low efficiency in terms of emissions reduction over the food-consumption changes (in other words, food consumption is more elastic); CAPRI shows opposite trends (Supplementary Fig. 9).

Regional implications. The impacts of the three mitigation measures for risk of hunger show similar patterns to the global results described in the prior section. In the baseline scenarios, the risk of hunger in most regions except for Sub-Saharan Africa is projected to decrease over time, mainly driven by long-term per capita income growth as shown in the global results, which might not be the case in the short term due to COVID-19. China and India show higher income growth than most other countries, and thus the risk of hunger rapidly decreases from 2010 to 2050 to 43.6 (21.4-70.0) million and 79.0 (22.6-100.0) million, respectively (Fig. 4a). Population at risk of hunger in African regions increases slightly from 164.5 million in 2010 to 167.2 (67.6-176) million in 2050, mainly due to population growth. In this time frame, Africa's share of the global total increases from $21.1 \%$ in 2010 to $31.2 \%$ (23.0-40.0\%). The relative impact of full emissions mitigation on the portion of the population at risk of hunger is generally similar across regions; still, the 

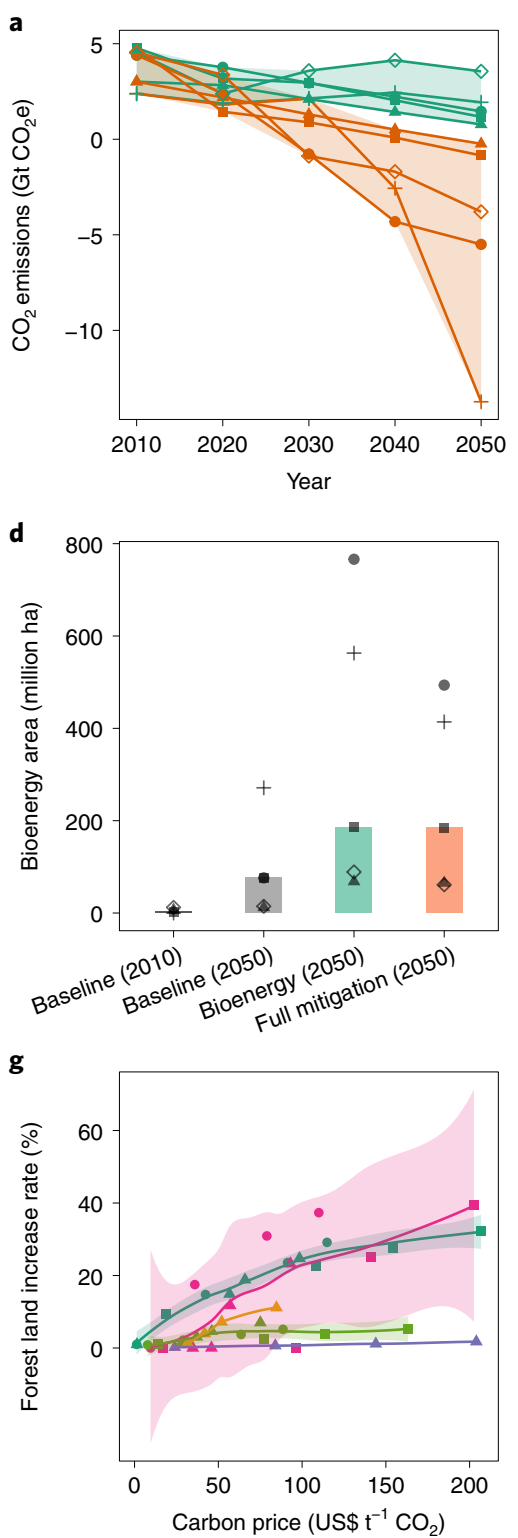
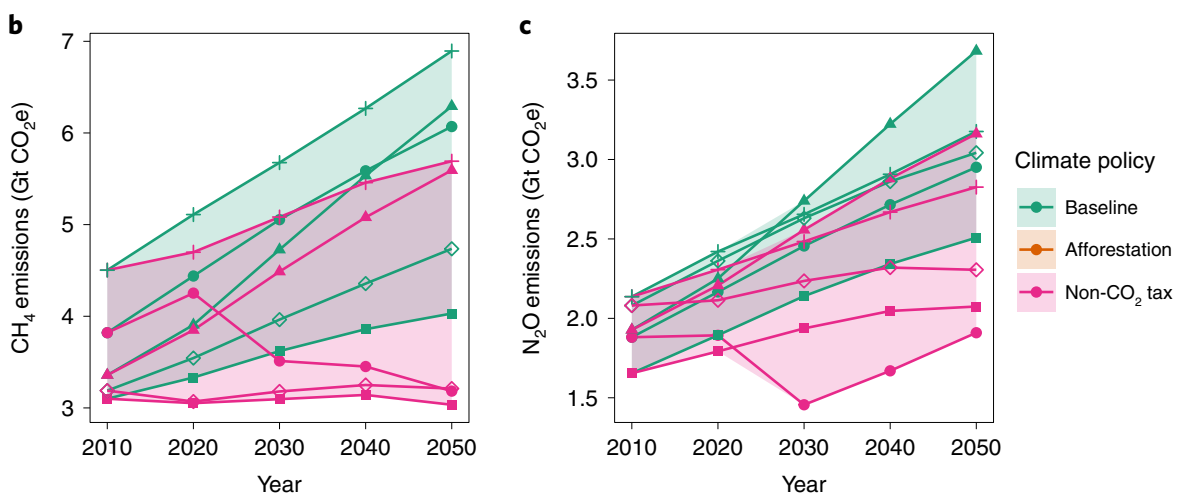

e
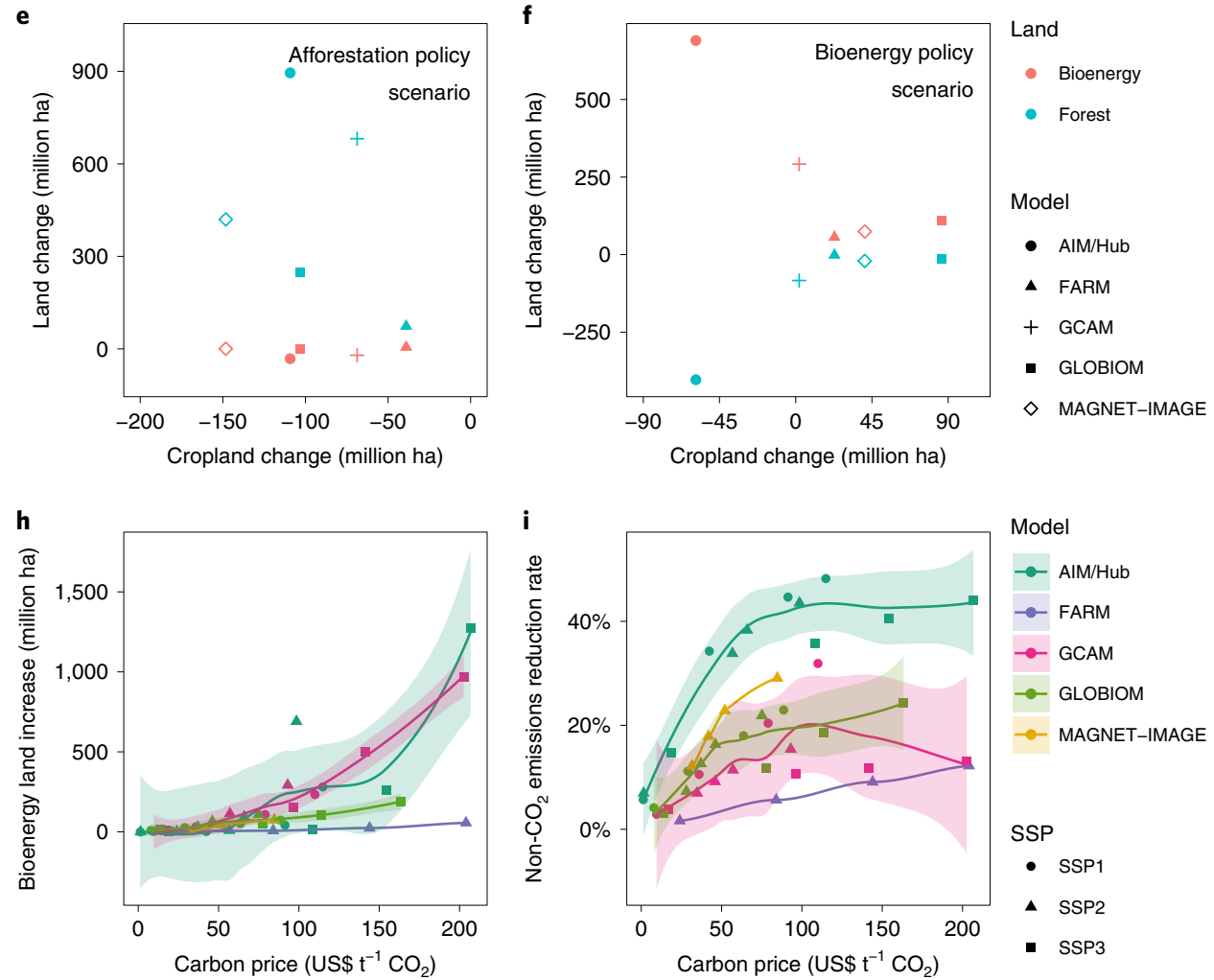

Fig. 3 | Various emissions. a-c, Global $\mathrm{CO}_{2}(\mathbf{a}), \mathrm{CH}_{4}(\mathbf{b})$ and $\mathrm{N}_{2} \mathrm{O}(\mathbf{c})$ emissions from AFOLU sectors with baseline, afforestation and non- $\mathrm{CO}_{2}$ policies. These emissions estimates are based on four models with complete scenarios and have SSP2 as a socioeconomic backdrop. $\mathbf{d}$, Bioenergy production land area is shown for each scenario. e,f, Afforestation policy scenario (e) and bioenergy policy scenario (f) illustrate the trade-offs among cropland area, bioenergy and forest-area changes in 2050. $\mathbf{g}-\mathbf{i}$, The relationships between carbon price and forest area ( $\mathbf{g}$ ), bioenergy area (h) and non- $\mathrm{CO}_{2}$ emissions reduction rates (i) are shown; non- $\mathrm{CO}_{2}$ emissions are converted to $\mathrm{CO}_{2} \mathrm{e}$ using the GWP100 (100-year global warming potential) in AR5. Results are based on five models with complete scenarios and six model results shown in Supplementary Fig. 10. The shaded areas and makers in panels a-c show model uncertainty ranges and individual model results, respectively. Those in panels $\mathbf{g}-\mathbf{i}$ show $95 \%$ confidence intervals and SSP variations, respectively.

absolute population at risk of hunger in any scenario and region largely depends on each region's baseline projection. Consequently, the African region has the largest population at risk of hunger in 2050 at 35.3 (10.5-69.5) million (Fig. 4a). The decomposition of three mitigation measures differs remarkably between Asian and African regions: Asian regions have relatively high impacts from non- $\mathrm{CO}_{2}$ emissions mitigation, whereas African regions show large impacts from afforestation policies. Asia has higher future income per capita than Africa (Supplementary Fig. 9), which leads to higher meat and dairy consumption (Supplementary Figs. 11 and 12), which entails prominent and difficult-to-abate non- $\mathrm{CO}_{2}$ emissions. Another contributing factor is land rent, which is generally lower in Africa than in Asia, and as such, a price on terrestrial carbon can be expected to have a greater impact in Africa. More detailed regional results are shown in Supplementary Fig. 13. Note that whereas the irrigated rice area in Asia is considerable and causes relatively high $\mathrm{CH}_{4}$ emissions, this is not the main driver of the above-mentioned land and commodity price changes (Supplementary Fig. 14).

Socioeconomic variations. Socioeconomic development is one of the key elements that determines future agricultural market and food security conditions. As such, we carried out a sensitivity test under different socioeconomic assumptions: SSP1 and SSP3, which span a wide range for the future (low population and high economic growth in SSP1 and high population and low economic development in SSP3) ${ }^{37}$. In baseline scenarios, the total population at risk of hunger decreases faster in SSP1 than SSP2 due to the rapid economic development, particularly in current low-income countries 

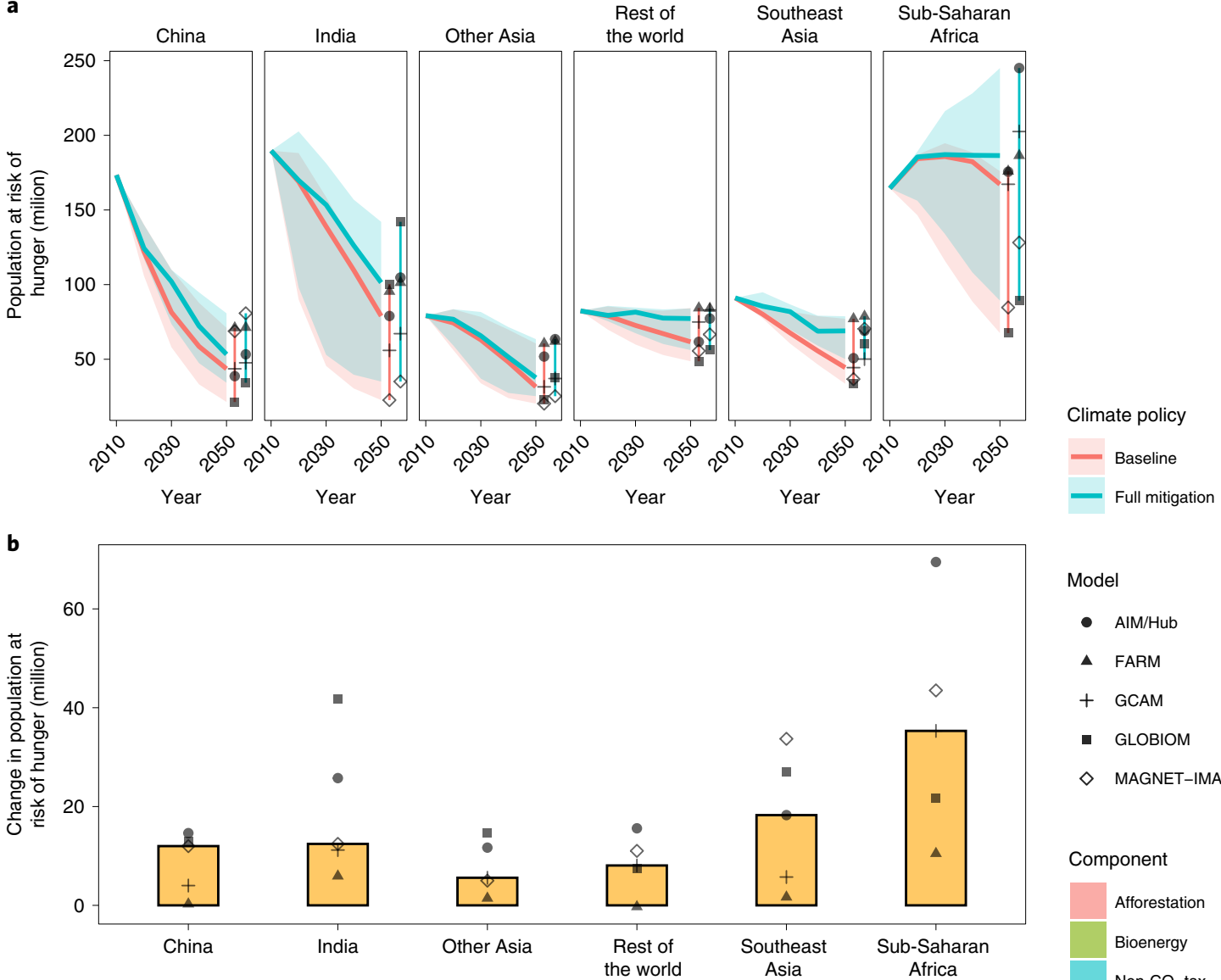

Model

- $\mathrm{AlM} / \mathrm{Hub}$

$\triangle$ FARM

+ GCAM

- GLOBIOM

$\diamond \quad$ MAGNET-IMAGE

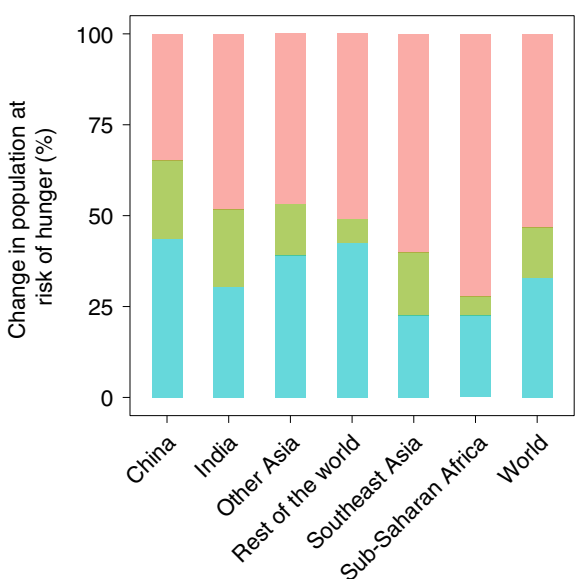

d

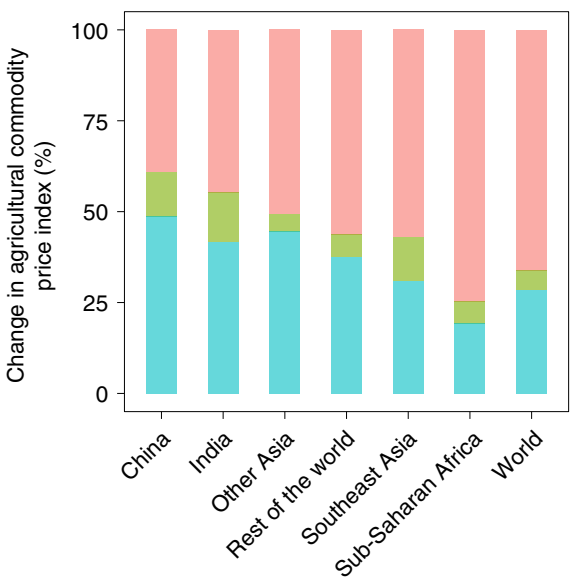

Fig. 4 | Regional effects of each land-based mitigation measure on risk of hunger and food price for SSP2. a, The population at risk of hunger over the period by region. The shaded area and solid lines indicate model uncertainty range and median value, respectively. $\mathbf{b}$, Changes in population at risk of hunger in the mitigation scenario relative to the baseline scenario. The orange boxes indicate the median values among models. $\mathbf{c}, \mathbf{d}$, Percentage share for each cause of change in population at risk of hunger and agricultural price index (regional definitions are provided in Supplementary Table 2).

in SSP1. Meanwhile, SSP3 shows the population at risk of hunger reacting opposite of SSP1's direction, generally increasing or at least maintaining present-day risk over the next couple of decades (Fig. $5 a)$. The response to the climate mitigation policies differs, and the risk of hunger in SSP1 and SSP3 increases by 61.1 (12.3-73.9) million and 359.3 (264.7-557.3) million compared with baseline scenarios respectively in 2050 . This could be partly due to the differences in baseline hunger projections, but more importantly, the risk of hunger in SSP3 should be more sensitive than others to the same carbon price because the average per capita income is low and thus there is a larger number of people in poverty. The percentage changes give clearer characteristics of SSPs; namely $28.4 \%$ (4.2$47.9 \%)$ and $46.1 \%(36.0-66.2 \%)$ in SSP1 and SSP3, respectively. Similar behaviour from agricultural commodity price changes is shown in Supplementary Fig. 7.

In contrast to the total effects of climate mitigation, the decomposition of three causes show similar trends in all SSPs (Fig. 5d-f). In SSP1, afforestation, bioenergy and non- $\mathrm{CO}_{2}$ abatement induce additional risk of hunger by 37.6 million, 3.0 million and 17.5 million (model medians, respectively), while in SSP3 they are 132.7 
a
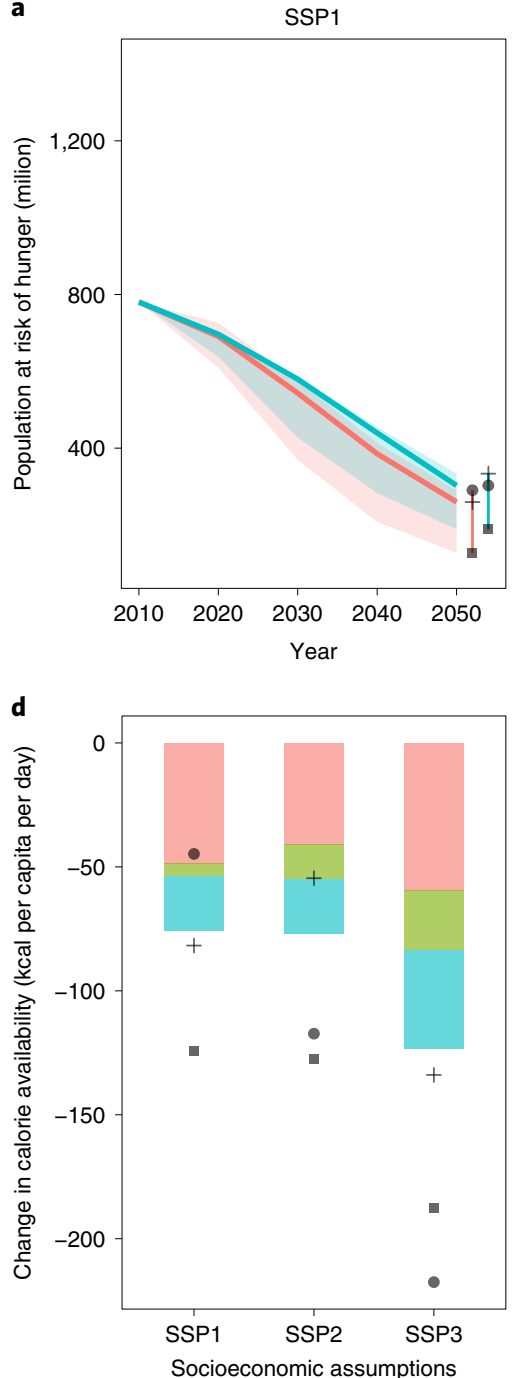

b
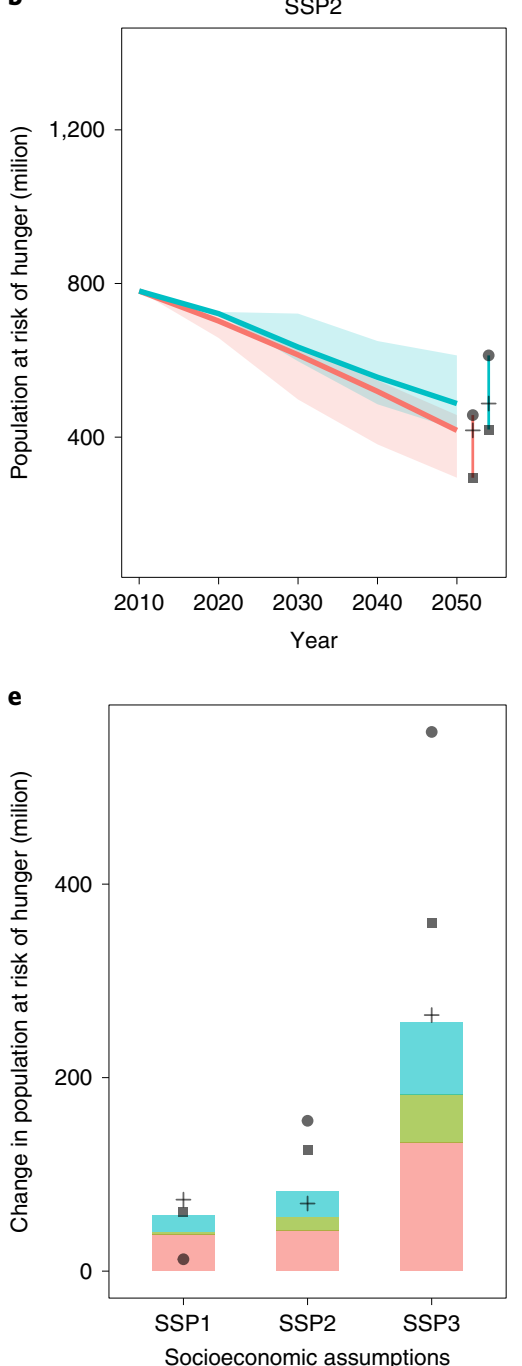

C

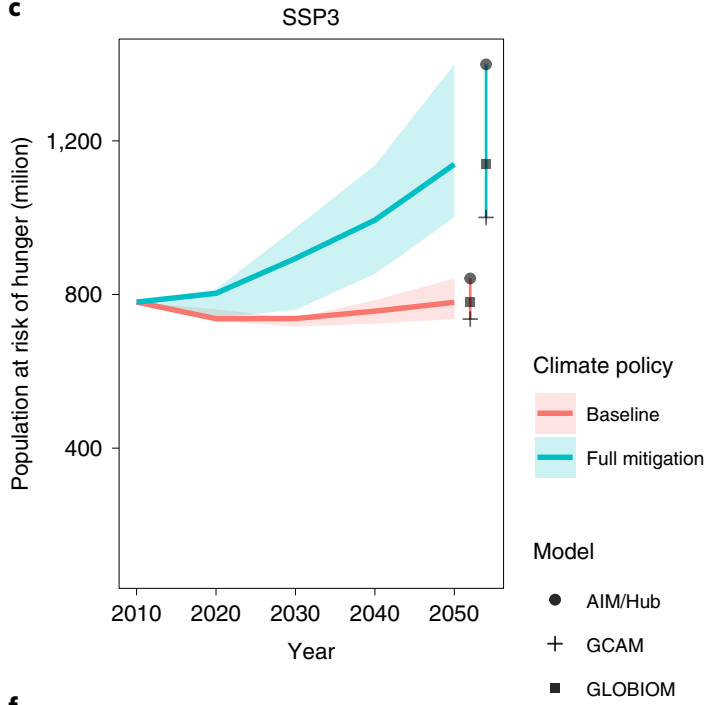

f

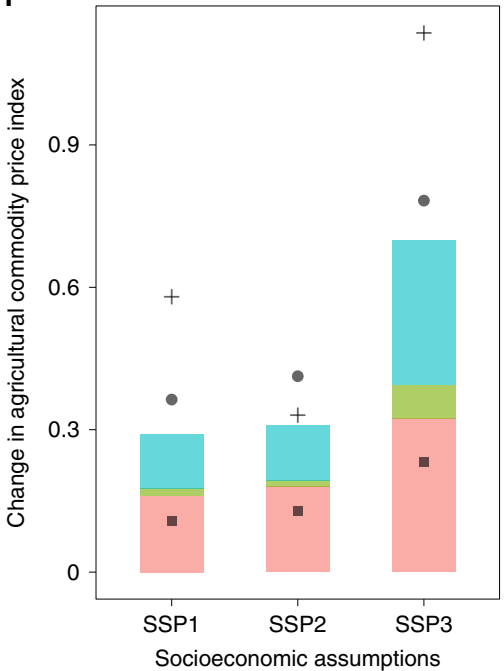

Component

Afforestation Bioenergy Non- $\mathrm{CO}_{2}$ tax

Fig. 5 | Socioeconomic uncertainties in food security indicators. a-c, SSP variations in global population at risk of hunger. The shaded area and solid lines indicate model uncertainty range and median value, respectively. $\mathbf{d}$-f, Change in food consumption (d), population at risk of hunger (e) and agricultural price index (f) in three SSPs in 2050.

million, 49.7 million and 74.4 million (model medians), respectively in 2050. This further supports our findings in SSP2 shown earlier. It can also be interpreted that regardless of future socioeconomic conditions, the afforestation and non- $\mathrm{CO}_{2}$ reductions are the main factors prescribing the impacts of emissions mitigation broadly on the agricultural sector.

\section{Discussions and Conclusions}

We have estimated the three main causes of food insecurity and agricultural commodity price and land-use changes associated with climate change mitigation measures, namely afforestation, bioenergy expansion and non- $\mathrm{CO}_{2}$ emissions abatement. Afforestation policies caused the greatest adverse side effects on food security, followed by non- $\mathrm{CO}_{2}$ abatement policies. We confirm this finding under different socioeconomic assumptions with multiple global agricultural economic models. We further demonstrate that specific extreme models do not lead our conclusion. Regionally, Sub-Saharan Africa is most vulnerable to these shocks. Our results indicate the complexity and challenges in AFOLU emissions mitigation policy from multiple angles. The actual risk of hunger in response to agricultural price increases or mean food-consumption decreases is difficult to elucidate due to the complex nature of hunger and poverty.
Our results require careful interpretation; however, the avoidance of this potential issue is worthy of consideration.

As shown in Fig. 1, a key element in the causal chain between emissions mitigation policy and food insecurity is the cost of agricultural commodity production. The most stringent climate-stabilization scenarios rely heavily on negative emissions technologies such as afforestation and BECCS, and mitigation of non- $\mathrm{CO}_{2}$ emissions is also quite important under low or net zero emissions conditions $s^{4,38}$. The carbon pricing on land carbon stock generally increases the land rent and motivates landowners to expand forests. The higher the carbon prices and forest primary productivity, the stronger this incentive is. These dynamics drive agricultural commodity production costs upward. Bioenergy production can trigger similar effects through generally similar causal mechanisms, increasing land rent due to the additional competition. Mitigating non- $\mathrm{CO}_{2}$ emissions has a different mechanism of increasing agricultural production costs; these policies directly increase the food crop production costs, both due to the cost of the abatement technologies deployed and the additional costs from any remaining emissions that are not abated. Nevertheless, non- $\mathrm{CO}_{2}$ mitigation measures impact more substantially a subgroup of sectors with higher emissions intensity per kcal, such as livestock products compared with afforestation 
that targets all cropland and grassland without distinction. Once climate policy would give incentives to these measures, it might be difficult to cut off the left arrows in Fig. 1. One possibility to prevent this situation would be societal transformation (for example, reducing energy demand drastically ${ }^{39}$ and/or lifestyle changes ${ }^{40}$ ). Although such outcomes are possible, they should not be assumed for present-day policy modelling and assessment.

The impact from these three drivers on the 'secondary factors', shown in Fig. 1 may be addressed through policy. For example, even if large-scale afforestation and bioenergy expansion occurs, land rent impacts on cropland could be controlled by policy such as subsidies for production of food crops. Note that without the carbon pricing on land carbon sinks, there would be strong incentives to cultivate bioenergy crops to attain negative emissions associated with BECCS; to deter this, policies related to non-food land demand may be needed ${ }^{41,42}$. Regarding the arrows from secondary effects to the production costs in Fig. 1, there are still important roles for policy, but technology can also help to mitigate any adverse impacts. One issue of subsidy policy in general is the scale of the market distortion; the scenarios show production cost increases by around $30 \%$ relative to baseline, which would require substantial subsidy budgets. Note that carbon tax revenue might be the right candidate for this purpose ${ }^{43}$. Technological progress in non- $\mathrm{CO}_{2}$ emissions reduction and bioenergy yield would mitigate the agricultural cost increases. Although it is essential to encourage the research and development of these technologies, progress on specific individual technologies is unpredictable; therefore, it is important to maintain or increase investment in this area in general.

Aside from the supply-side management, demand-side transitions may mitigate the adverse side effects such as dietary shifts reducing meat consumption ${ }^{44,45}$, changing food distribution practices to better meet the needs of the most vulnerable, reducing food waste or implementing subsidies for consumption ${ }^{14,46}$. In particular, the scale of subsidy is reported to be small, and despite the challenges associated with the implementation of food policies, several options are available to avoid the food security concerns often linked to climate mitigation. Alternatively, a reduction in food waste may have considerable potential since food waste volume is currently substantial. In any case, the above-mentioned measures may not be effective in isolation. We would need holistic approaches for food security under deep decarbonization transition. Note that trade is understood to be important for resolving discrepancies between supply and demand and mitigating price shocks; however, at least within the framework of our study, trade alone does not resolve these issues because climate policy (that is, carbon price) is implemented globally. If trade barriers were alleviated, the adverse effects of climate change mitigation on hunger risk would be moderated. However, such a decision would impact the baseline scenario design.

Whereas the main results of this study were true for most-if not all-participating models, it is worth noting that some of the variability in the results may be explained by the models' structural representations. For example, models that show relatively high impacts of afforestation policies are AIM/Hub, GCAM and MAGNETIMAGE, all of which have explicit representations of land rent, and in all cases, the emissions mitigation policies with afforestation led to remarkable increases in land rental rates due to the pricing of terrestrial carbon. In contrast, GLOBIOM has no explicit land rent, and the cost increase in agricultural commodities is instead caused by a shift in cropland from high- to low-productivity land areas. In addition to structural differences, there is also notable uncertainty that is due to different parameterization; for example, models with similar structural land nesting can return dramatically different results if using different elasticities. A previous study compared IAM model performance based on a sensitivity analysis of specific parameters but focused mainly on land-use changes ${ }^{30}$; a similar analysis focused on hunger risk should be conducted in a future study.
Whereas in this study we focused on agricultural and food security aspects, the policies analysed also probably have ancillary impacts, some positive (for example, biodiversity, ecosystem services) and some negative (for example, eutrophication). Reforestation with native species can have additional environmental co-benefits in regenerating habitat ${ }^{47}$. In contrast, if the afforestation purely aims to sequester the maximum possible amount of carbon from the atmosphere, the tree species selected might be non-native and cause negative ecosystem impacts. Some models represent entire economic systems, including general equilibrium effects (for example, labour allocation changes, consumption of other goods, price changes and macroeconomic feedbacks); such effects have only partly been addressed in the literature ${ }^{11,48,49}$. Moreover, nitrogen pollution and water consumption may be exacerbated by climate change mitigation $^{50-52}$; more comprehensive and geographically detailed environmental assessment would allow such an analysis. Finally, the models used in this study require continuous model-improvement efforts such as validation of the assumed parameters to better reflect historical trends. We also see several large differences in base year (for example, land-use data), and future studies should invest some effort in making those differences smaller.

\section{Methods}

We carried out a scenario analysis to decompose the effects of afforestation, bioenergy and non- $\mathrm{CO}_{2}$ abatement on agricultural markets and food security. The overall research framework is shown in Supplementary Fig. 1. For this scenario analysis, we employed six state-of-the-art global agricultural economic or integrated assessment models that sufficiently represent the agricultural sector and land use to assess the interaction between climate mitigation and food security. Global economic models compute the agricultural consumption, production, land use and associated emissions by crops and livestock and forestry. Food-consumption data from the models are then provided to a hunger assessment tool, which computes individual countries' food-consumption distribution and population at risk of hunger. To identify the magnitude of three causes on the agricultural market, we developed a sensitivity scenario protocol that involved systematically switching on/off the different mitigation options. Basically, the models react to mitigation policies that cause the prices of agricultural commodities to increase because of agricultural production-cost increases. While this price change can induce food-consumption shifts such as from rice to other cereals, the total food consumption decreases. Here we describe (1) the scenario definition and protocol, (2) a brief model overview for each agricultural model (a summary is in Supplementary Table 1) and (3) the hunger tool description.

Scenarios and experiment design. We developed a set of scenarios that combine three socioeconomic conditions and one mitigation policy scenario (and one baseline scenario) that are consistent with the $2{ }^{\circ} \mathrm{C}$ goal stated in the Paris Agreement, which is equivalent to the RCP2.6 level of emissions reduction for the main assessment ${ }^{53}$. These mitigation policy scenarios include a variety of land-based abatement options but apply the same carbon prices. For the socioeconomic assumptions, we used three SSPs from the internationally developed SSP framework designed to conduct cross-sectoral assessments of climate change impact, adaptation and mitigation ${ }^{29}$. The SSPs are representative future scenarios, which include both qualitative and quantitative information in terms of challenges in mitigation and adaptation to climate change. In this study, we used three SSP scenarios from the SSP framework, that is, 'sustainability' $(\mathrm{SSP} 1)^{26}$, 'middle of the road' (SSP2) ${ }^{54}$ and 'regional rivalry pathways' (SSP3) ${ }^{21}$ to address the uncertainty of socioeconomic conditions (Supplementary Fig. 15). We implement SSP-dependent agricultural yield, food preference and so on beyond population and gross domestic product as shown in Stehfest et al. ${ }^{30}$ We did not explicitly represent additional land-degradation effects in our crop yield projection (Supplementary Fig. 16), although these are of concern ${ }^{55,56}$. They are basically in line with the historical trends while there are variations among regions and crops $^{57}$. These are wholly model-dependent assumptions that we did not harmonize, and thus it is natural that variation should emerge. There are some responses to mitigation policies which are quite limited because we assume that climate conditions are unchanged. Incorporating these effects could change the numerical results, reducing the amount of arable land available for energy crops or afforestation, ultimately decreasing mitigation potential. Incorporating land-recovery effects would produce the opposite results.

To isolate the effect of each land-based mitigation option (afforestation, bioenergy and non- $\mathrm{CO}_{2}$ emissions reduction plus carbon-price imposition), we used a recently developed ${ }^{58,59}$ and widely applied methodology $y^{30}$ that identifies the individual effects of an input factor with a limited number of model experiments even in a complex system. In general, we could classify the mitigation options into 
four categories, that is, afforestation, bioenergy, non- $\mathrm{CO}_{2}$ pricing and other (tax on non-agriculture and land-use sectors). The first three are land-related mitigation options and are the focus of this study. Therefore, we designed three scenarios with each applying only one of the land-related mitigation options and one scenario that applies all three options simultaneously, as shown in Supplementary Table 3 (for the models with non-agricultural sectoral emissions-for example, energy sectors-including AIM/Hub, GCAM and FARM, because it is difficult to turn off these mitigation options, tax on non-agricultural sectoral emissions was also applied in these four scenarios).

Both the baseline and mitigation scenarios are sub-optimal scenarios in terms of agricultural productivity, production and consumption structure from the perspective of reducing hunger risk and achieving emissions abatement at the lowest cost. There can be non-economic barriers to fulfilling the optimal condition (for example, filling the yield gap and realizing environmentally friendly dietary patterns). If climate change mitigation policy packages could be designed to change the assumed socioeconomic conditions simultaneously, underlying the baseline scenarios, then both the population at risk of hunger and GHG emissions would decrease.

We have also run sensitivity scenarios with AIM/Hub, FARM and GLOBIOM, where most mitigation measures are available and only one is switched off; each of these models sufficiently represents all agricultural activities and GHG emissions (Supplementary Tables 1 and 3). Note that while non- $\mathrm{CO}_{2}$ emissions from agricultural sectors are fully covered, soil organic carbon, emissions due to biomass burning associated with land clearing and changes in agricultural biomass are not considered. This exercise could enhance the robustness of our decomposition methodology, which is similar to the way carried out by other studies in the climate change analysis literature ${ }^{30,60}$ (Supplementary Table 4). However, it should be noted that because there are individual model characteristics, there can be some biases originated from model representations. For example, multiple cropping is represented in four out of six models. For all mitigation scenarios, a global uniform carbon tax (except for FARM, which applies an endogenous carbon price) was imposed in these mitigation scenarios ${ }^{54}$, as shown in Supplementary Fig. 2. Model submission status is shown in Supplementary Table 5.

Regarding non-agricultural sectors' interactions, models without representation of non-agricultural sectors (CAPRI, GLOBIOM and MAGNET-IMAGE) can be assessed by directly comparing baseline and mitigation scenarios. For the models with representation of non-agricultural sectors (AIM/Hub, GCAM and FARM), we need to further identify the effect of non-agricultural activity (for example macroeconomic feedback associated with energy system changes) and thus we run all mitigation measures off scenarios (Supplementary Table 6). The final result presented was the average of scenario sets and decomposition method, which aimed to account for the uncertainty in modelling capacity and decomposition method. For bioenergy, Supplementary Table 7 shows model output.

We show the main baseline indicators for crop production (Supplementary Fig. 17), livestock production (Supplementary Fig. 18), food consumption (Supplementary Fig. 19), population at risk of hunger (Supplementary Fig. 20), agricultural price index (Supplementary Fig. 21), cropland (Supplementary Fig 22 ), pastureland and its changes relative to baseline scenarios (Supplementary Figs. 23 and 6), land-use composition (Supplementary Fig. 24), food use ratio for coarse grain (Supplementary Fig. 25) and ruminant meat consumption share in total meat consumption (Supplementary Fig. 26; note that this trend may not fully reflect the recent historical decreasing trend).

Model description. This section describes the main features of each model Because many models used in this study participated in the earlier studies (for example, ref. ${ }^{13}$ ), this section can be similar to the description in those papers ${ }^{13}$.

$\mathrm{AIM} / \mathrm{Hub}^{21}$, which is formerly named AIM/CGE, is a one year step recursive-type dynamic general equilibrium model that covers all regions of the world. The AIM/Hub model includes 17 regions and 42 industrial classifications. For appropriate assessment of bioenergy and land-use competition, agricultural sectors are also highly disaggregated ${ }^{61}$. Details of the model structure and mathematical formulae are described by Fujimori, Masui and Matsuoka ${ }^{62}$. The production sectors are assumed to maximize profits under multi-nested constant elasticity substitution functions and each input price. Energy-transformation sectors input energy and value added are fixed coefficients of output. They are treated in this manner to deal with energy conversion efficiency appropriately in the energy-transformation sectors. Power generation values from several energy sources are combined with a logit function. This functional form was used to ensure energy balance because the constant elasticity substitution function does not guarantee an energy balance. Household expenditures on each commodity are described by a linear expenditure system function. The parameters adopted in the linear expenditure system function are recursively updated by income elasticity assumptions $s^{27}$. Land use is determined by logit selection ${ }^{61}$. Land-use change emissions are derived from the forest-area change relative to the previous year multiplied by the carbon stock density, which is differentiated by global agroecological zones. Non-energy related emissions other than land-use change emissions are assumed to be in proportion to the level of each activity (such as output). $\mathrm{CH}_{4}$ has a range of sources, mainly the rice production, livestock, fossil fuel mining and waste-management sectors. $\mathrm{N}_{2} \mathrm{O}$ is emitted as a result of fertilizer application and livestock manure management and by the chemical industry.
MAGNET-IMAGE (Modular Applied GeNeral Equilibrium Tool-Integrated Model to Assess the Global Environment) is the combination of the agroeconomic model MAGNET ${ }^{63}$ and the integrated assessment model IMAGE ${ }^{64}$. MAGNET is a multi-regional, multi-sectoral, applied general equilibrium model ${ }^{64}$ based on neo-classical microeconomic theory which is an extension of the standard Global Trade Analysis Project (GTAP) model. The core of MAGNET is an input-output model, which links industries in value-added chains from primary goods to final goods and services for consumption. Input and output prices are endogenously determined by the markets to achieve supply and demand equilibrium. The agricultural sector is represented in high detail compared with standard CGE models. Developments in productivity are driven by a combination of assumptions on autonomous technological change provided by IMAGE and by economic processes as modelled by MAGNET (that is, substitution between production factors). Land is modelled as an explicit production factor described by a land supply curve, constructed with land availability data provided by IMAGE.

IMAGE is a comprehensive integrated assessment framework, modelling interactions between the human and natural systems ${ }^{64}$. The framework comprises a number of sub-models describing land use, agricultural economy, the energy system, natural vegetation, hydrology and the climate system. In this study, specifically, the land component is applied, which represents land use, crop production, afforestation and the carbon cycle spatially explicitly at a 5 arc-minute resolution

Emissions in MAGNET are coupled to all relevant sectors. Technical mitigation of non- $\mathrm{CO}_{2}$ GHG emissions from agriculture is based on Lucas et al. ${ }^{65}$ The residual emissions are taxed in MAGNET. The costs of technical mitigation are also implemented as part of the tax. The level of avoided deforestation and afforestation policy is determined in IMAGE through the climate policy model FAIR-SimCAP that makes a cost-effectiveness assessment of these mitigation options compared with other options in the energy and industry sectors ${ }^{16}$. The policy measures are subsequently implemented in MAGNET through reduced land availability.

GLOBIOM (GLobal BIOsphere Management) model, which is a partial equilibrium model ${ }^{66}$, represents the competition between different land use-based activities. It includes a detailed representation of the agricultural, forestry and bioenergy sectors, which allows for the inclusion of detailed grid-cell information on biophysical constraints and technological costs and a rich set of environmental parameters, including comprehensive AFOLU GHG emission accounts and irrigation water use. For spatially explicit projections of the change in afforestation deforestation, forest management and their related $\mathrm{CO}_{2}$ emissions, GLOBIOM is coupled with G4M (Global FORest Model) ${ }^{67}$. As outputs, G4M provides estimates of forest-area change, carbon uptake and release by forests and supply of biomass for bioenergy and timber.

GCAM integrated assessment model links modules of the economy, energy system, agriculture and land-use system and climate ${ }^{68-70}$. The agriculture and land-use component determines supply, demand and prices for crop, animal and forestry production and bioenergy based on expected profitability. In doing so, the model determines land allocation across these categories and pastureland, grassland, shrubland and noncommercial forestland. The agriculture and land-use component of GCAM is fully coupled with the energy, economic and climate modules within GCAM; that is, all four components are solved simultaneously. In the version of GCAM used in this study, bioenergy provides the primary linkage between the agriculture and land-use component and the energy component, with bioenergy produced by the land system and consumed by the energy system. The agriculture and land component is coupled to the energy economy through bioenergy and carbon prices. Carbon prices are imposed iteratively until the prescribed climate target is reached. The carbon prices influence the cost of fossil fuel energy technologies, and the profitability of land-cover options. In particular, GCAM assumes the carbon price is applied to carbon stocks held in the terrestrial system, incentivizing land owners to increase these stocks. As a result, strong incentives exist to expand carbon stocks under a climate policy, resulting in substantial afforestation. The agriculture and land-use component is connected to the climate through emissions $\left(\mathrm{CO}_{2}\right.$ and non- $\left.\mathrm{CO}_{2}\right)$, which are produced by the land system and passed into the climate system to calculate concentrations, radiative forcings and other climate indicators.

CAPRI (Common Agricultural Policy Regionalised Impact) modelling system is an economic large-scale, comparative-static, partial equilibrium model focusing on agriculture and the primary processing sectors (www.capri-model.org). CAPRI comprises two interacting modules, linking a set of mathematical programming models of EU regional agricultural supply to a spatial multi-commodity model for global agri-food markets. The regional EU supply models depict a profit-maximizing behaviour of representative farms for all EU NUTS 2 regions (that is, the nomenclature of territorial units for statistics is a hierarchical system developed by EUROSTAT for dividing up the economic territory of the European Union), taking constraints related to land availability, nutrient balances for cropping and animal activities and policy restrictions into account. The market module consists of a spatial, non-stochastic global multi-commodity model for about 60 primary and processed agricultural products, covering 77 countries in 40 trading blocks. Bilateral trade flows and attached prices are modelled based on the Armington assumption of quality differentiation ${ }^{71}$. The behavioural functions in the market model represent supply and demand for primary agricultural and 
processed commodities (including human and feed consumption, biofuel use and import demand from multilateral trade relations), balancing constraints and agricultural market policy instruments (that is, import tariffs, tariff rate quotas, producer and consumer support estimates and so on). With regard to GHG accounting, CAPRI calculates EU agricultural GHG emissions for the most important $\mathrm{N}_{2} \mathrm{O}$ and $\mathrm{CH}_{4}$ emission sources based on the inputs and outputs of agricultural production activities, following to a large extent the 2006 Intergovernmental Panel on Climate Change guidelines. It also includes specific technical and management-based GHG mitigation options for EU agriculture into account. GHG emissions for the rest of the world are estimated on a commodity basis in the market model ${ }^{72}$

FARM (Future Agricultural Resources Model) is a global computable general equilibrium (CGE) model with 13 world regions that operates in five-year steps from 2011 to $2101^{73}$. Data requirements include a base-year social accounting matrix from GTAP at Purdue University, energy balances from the International Energy Agency, land use from the Food and Agriculture Organization (FAO) of the United Nations and agricultural production from FAO. FARM has been extended in many ways beyond the 'GTAP in GAMS' model described in Lanz and Rutherford ${ }^{74}$ : conversion from comparative-static to a recursive-dynamic framework; conversion of the consumer demand system from constant elasticity of substitution to the linear expenditure system; allowing for joint products in production functions; introduction of land classes for agricultural and forestry production; and introduction of electricity-generating technologies. Two markets are important for bioelectricity: the market for land and the market for electricity Bioelectricity must compete against crops, pasture and forest for land, and must also compete for a share of electricity generation. Land shifts among crops, pasture and forests in response to population growth, dietary preference, changes in agricultural productivity and policies such as a renewable portfolio standard or a carbon tax. Land competition is based on the land rent for each competing use: land use is adjusted within agroecological zones until rents at the margin are equal. The relatively simple market-clearing conditions for land allocation may not accurately represent the current heterogeneous land market; at the same time, however, this representation has the advantage of maintaining the land area's physical balance. $\mathrm{CO}_{2}$ capture and storage is available for electricity generated from fossil fuels and from bioelectricity.

Model characteristics. Each model has individual characteristics that include advantages and disadvantages. Here we briefly describe them. CGE models, AIM/ Hub, FARM and MAGNET have the advantage of being able to take into account the whole economic system with interaction of macroeconomic feedback and microeconomic price adjustments. AIM/Hub and FARM explicitly represent energy systems and emissions in physical terms. This enables them to consistently deal with the energy market, including bioenergy substitution with other energy carriers for energy demand and energy supply (bioenergy power generation) and consistent GHG emissions. MAGNET does not represent them, which could be a potential disadvantage, but it compensates for this by linking to the IMAGE model. Meanwhile, CGE models mostly have relatively coarse agricultural sector resolutions compared with partial equilibrium models, which may sometimes be a disadvantage. Within the partial equilibrium models, GCAM and other models (CAPRI and GLOBIOM) differ significantly in the sense that GCAM includes energy systems and their emissions explicitly with detailed technological resolutions. As indicated earlier, this characteristic can provide a physically consistent picture of energy, agriculture and land-use interactions. CAPRI and GLOBIOM have relatively detailed sectoral and spatial resolutions that allow exploration of food production and consumption details, which is usually a strong advantage. GLOBIOM offers an advanced representation of livestock production systems and forestry.

Estimates of people at risk of hunger. In principle, the risk of hunger can be calculated by referring to the mean calorie consumption, which is the same approach as in AIM/Hub and IMAGE. The narrow definition of undernourishment or hunger is a state of energy (calorie) deprivation lasting over one year; this does not include the short-lived effects of temporary crises ${ }^{75,76}$. Furthermore, this does not include inadequate intake of other essential nutrients ${ }^{75}$. The population at risk of hunger is a proportion of the total population and is calculated using equation (1):

$$
\text { Risk }_{t}=\mathrm{POP}_{t} \times \mathrm{PoU}_{t}
$$

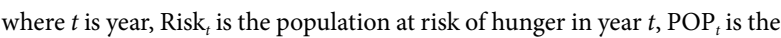
population in year $t$ and $\mathrm{PoU}_{t}$ is the proportion of the population at risk of hunger in year $t$.

According to FAO methodology $y^{77}$, the proportion of the population at risk of hunger is defined using equations (2)-(4). With the FAO methodology, the proportion is calculated using three parameters: the mean food calorie consumption per person per day (cal), the mean minimum dietary energy requirement $(M)$ and the coefficient of variation of the food distribution of the dietary energy consumption in a country (CV). The food distribution within a country is assumed to follow a log normal distribution. The proportion of the population under the mean minimum dietary energy requirement $(M)$ is defined as the proportion of the population at risk of hunger. The log normal distribution has two parameters, the mean $\mu_{t}$ and the variance $\sigma_{t}$ as in equation (2). The parameters $\mu_{t}$ and $\sigma_{t}$ can be represented using the mean food calorie consumption per person per day $(\mathrm{cal})$ and the coefficient of variation of the domestic distribution of dietary energy consumption (CV) as in equations (3) and (4).

Each IAM reports the mean food calorie consumption per person per day (cal). We standardize the base-year calorie consumption to what FAO reports and take the change ratio of each year to the base year for IAMs. We then compute the standardized calorie consumption to make a consistent number for those at risk of hunger. In this process, because the IAMs are regionally aggregated values, they are downscaled to the individual country level by taking the base-year value reported by FAO and future change ratio from IAMs. The CV is an indicator of food security observed in a household survey conducted by the FAO. It ranges from 0 to 1 . FAO country data for $\mathrm{CV}$ are weighted on the basis of population data in the base year and aggregated to regional classification to obtain the $\mathrm{CV}$ of aggregated regions. The $\mathrm{CV}$ is changed over time with the consideration of income growth dynamics as presented in Hasegawa et al ${ }^{27}$ Note that there is an assumption that the future $\mathrm{CV}$ changes of each region is based on the current regional value.

$$
\begin{gathered}
\mathrm{PoU}_{t}=\Phi\left(\log M_{t}-\frac{\mu\left(\mathrm{cal}_{t}, \sigma_{t}\right)}{\sigma_{t}}\right) \\
\mu\left(\mathrm{cal}_{t}, \sigma_{t}\right)=\log \mathrm{cal}_{t}-\frac{\sigma_{t}^{2}}{2} \\
\sigma_{t}=\left[\log _{e}\left(\mathrm{CV}^{2}+1\right)\right]^{0.5}
\end{gathered}
$$

where $M_{t}$ is the mean minimum dietary energy requirement in year $t, \mathrm{CV}_{t}$ is the coefficient of variation of the international distribution of dietary energy consumption in year $t, \Phi$ is the standard normal cumulative distribution and $\mathrm{cal}_{t}$ is the mean food calorie intake per person per day in year $t$.

The mean minimum dietary energy requirement $(M)$ is calculated for each year and country by using the mean minimum dietary energy requirement in the base year at the country level ${ }^{78-80}$ and an adjustment coefficient for the minimum energy requirements per person in different age and sex groups ${ }^{79}$ and the population of each age and sex group in each year ${ }^{80}$, as in equations (5) and (6).

$$
\begin{gathered}
M_{t}=M_{\text {base }} \times \frac{\mathrm{MER}_{t}}{\mathrm{MER}_{\text {base }}} \\
\operatorname{MER}_{t}=\frac{\sum_{i, j} R M E R_{i, j} \times P_{\text {class }_{i, t}}}{\sum_{i, j} P_{\text {class }_{i, j}}}
\end{gathered}
$$

where $i$ is age group, $j$ is sex, $M_{\text {base }}$ is the mean minimum dietary energy requirement per person in the base year, $\mathrm{MER}_{t}$ is the mean adjustment coefficient of minimum energy requirements per person in year $t, \mathrm{MER}_{\text {base }}$ is the mean adjustment coefficient of the minimum energy requirements per person in the base year, $R M E R_{i, j}$ is the adjustment coefficient for the minimum energy requirements per person of age $i$ and sex $j$ and $P_{\text {class }_{i, j, t}}$ is the population of age $i$ and sex $j$ in year $t$.

Reporting Summary. Further information on research design is available in the Nature Research Reporting Summary linked to this article.

\section{Data availability}

Model output data are available at https://doi.org/10.5281/zenodo.5793100. Data derived from the original scenario database, which are shown as figures but are not in the above database, are available upon reasonable request from the corresponding authors. Source data are provided with this paper.

\section{Code availability}

All code used for data analysis and creating the figures is available via Zenodo at https://zenodo.org/record/5793100\#.YcB0w2jP2Uk.

Received: 14 December 2020; Accepted: 18 January 2022; Published online: 24 February 2022

\section{References}

1. Blanco, G. et al. Drivers, Trends and Mitigation (Cambridge Univ. Press, 2014).

2. Fuss, S. et al. Negative emissions-part 2: costs, potentials and side effects. Environ. Res. Lett. 13, 063002 (2018).

3. Popp, A., Lotze-Campen, H. \& Bodirsky, B. Food consumption, diet shifts and associated non- $\mathrm{CO}_{2}$ greenhouse gases from agricultural production. Glob. Environ. Change 20, 451-462 (2010).

4. Harmsen, J. H. M. et al. Long-term marginal abatement cost curves of non- $\mathrm{CO}_{2}$ greenhouse gases. Environ. Sci. Policy 99, 136-149 (2019). 
5. Hasegawa, T. \& Matsuoka, Y. Climate change mitigation strategies in agriculture and land use in Indonesia. Mitig. Adapt. Strateg. Glob. Change 20, 409-424 (2015).

6. Global Mitigation of Non- $\mathrm{CO}_{2}$ Greenhouse Gases: 2010-2030 (US Environmental Protection Agency, 2013).

7. Hasegawa, T. et al. Risk of increased food insecurity under stringent global climate change mitigation policy. Nat. Clim. Change 8, 699-703 (2018).

8. Fuss, S. et al. Betting on negative emissions. Nat. Clim. Change 4, 850-853 (2014).

9. Gambhir, A., Butnar, I., Li, P.-H., Smith, P. \& Strachan, N. A review of criticisms of integrated assessment models and proposed approaches to address these, through the lens of BECCS. Energies 12, 1747 (2019).

10. Gough, C. et al. Challenges to the use of BECCS as a keystone technology in pursuit of $1.5^{\circ} \mathrm{C}$. Glob. Sustain. 1, e5 (2018).

11. Hasegawa, T. et al. Consequence of climate mitigation on the risk of hunger. Environ. Sci. Technol. 49, 7245-7253 (2015)

12. Hasegawa, T. et al. Food security under high bioenergy demand toward long-term climate goals. Climatic Change 163, 1587-1601 (2020).

13. Fujimori, S. et al. A multi-model assessment of food security implications of climate change mitigation. Nat. Sustain. 2, 386-396 (2019).

14. Fujimori, S. et al. Inclusive climate change mitigation and food security policy under $1.5^{\circ} \mathrm{C}$ climate goal. Environ. Res. Lett. 13, 074033 (2018).

15. Frank, S. et al. Agricultural non- $\mathrm{CO}_{2}$ emission reduction potential in the context of the $1.5^{\circ} \mathrm{C}$ target. Nat. Clim. Change 9, 66-72 (2019).

16. Doelman, J. C. et al. Afforestation for climate change mitigation: potentials, risks and trade-offs. Glob. Change Biol. 26, 1576-1591 (2020).

17. Humpenöder, F. et al. Investigating afforestation and bioenergy CCS as climate change mitigation strategies. Environ. Res. Lett. 9, 064029 (2014).

18. Golub, A. A. et al. Global climate policy impacts on livestock, land use, livelihoods, and food security. Proc. Natl Acad. Sci. USA 110, 20894-20899 (2013)

19. Hussein, Z., Hertel, T. \& Golub, A. Climate change mitigation policies and poverty in developing countries. Environ. Res. Lett. 8, 035009 (2013).

20. Peña-Lévano, L. M., Taheripour, F. \& Tyner, W. E. Climate change interactions with agriculture, forestry sequestration, and food security. Environ. Resour. Econ. 74, 653-675 (2019).

21. Fujimori, S. et al. SSP3: AIM implementation of Shared Socioeconomic Pathways. Glob. Environ. Change 42, 268-283 (2017).

22. Thompson, W. et al. Long-term crop productivity response and its interaction with cereal markets and energy prices. Food Policy 84, 1-9 (2019).

23. Sands, R. D., Förster, H., Jones, C. A. \& Schumacher, K. Bio-electricity and land use in the Future Agricultural Resources Model (FARM). Climatic Change 123, 719-730 (2013).

24. Calvin, K. et al. The SSP4: a world of deepening inequality. Glob. Environ. Change 42, 284-296 (2017).

25. Fricko, O. et al. The marker quantification of the Shared Socioeconomic Pathway 2: a middle-of-the-road scenario for the 21st century. Glob. Environ. Change 42, 251-267 (2017)

26. van Vuuren, D. P. et al. Energy, land-use and greenhouse gas emissions trajectories under a green growth paradigm. Glob. Environ. Change 42, 237-250 (2017).

27. Hasegawa, T., Fujimori, S., Takahashi, K. \& Masui, T. Scenarios for the risk of hunger in the twenty-first century using Shared Socioeconomic Pathways. Environ. Res. Lett. 10, 014010 (2015).

28. Hasegawa, T., Fujimori, S., Takahashi, K., Yokohata, T. \& Masui, T. Economic implications of climate change impacts on human health through undernourishment. Climatic Change 136, 189-202 (2016).

29. Riahi, K. et al. The Shared Socioeconomic Pathways and their energy, land use, and greenhouse gas emissions implications: an overview. Glob. Environ Change 42, 153-168 (2017).

30. Stehfest, E. et al. Key determinants of global land-use projections. Nat. Commun. 10, 2166 (2019).

31. Hasegawa, T. et al. Extreme climate events increase risk of global food insecurity and adaptation needs. Nat. Food 2, 587-595 (2021).

32. Hasegawa, T., Fujimori, S., Takahashi, K. \& Masui, T. Scenarios for the risk of hunger in the twenty-first century using Shared Socioeconomic Pathways. Environ. Res. Lett. 10, 014010 (2015)

33. von Lampe, M. et al. Why do global long-term scenarios for agriculture differ? An overview of the AgMIP Global Economic Model Intercomparison. Agric. Econ. 45, 3-20 (2014)

34. Harmsen, M. et al. The role of methane in future climate strategies: mitigation potentials and climate impacts. Climatic Change 163, 1409-1425 (2020).

35. Gernaat, D. E. H. J. et al. Understanding the contribution of non-carbon dioxide gases in deep mitigation scenarios. Glob. Environ. Change 33 142-153 (2015).

36. Daioglou, V., Doelman, J. C., Wicke, B., Faaij, A. \& van Vuuren, D. P. Integrated assessment of biomass supply and demand in climate change mitigation scenarios. Glob. Environ. Change 54, 88-101 (2019).
37. Popp, A. et al. Land-use futures in the shared socio-economic pathways. Glob. Environ. Change 42, 331-345 (2017)

38. Rogelj, J., Meinshausen, M., Schaeffer, M., Knutti, R. \& Riahi, K. Impact of short-lived non- $\mathrm{CO}_{2}$ mitigation on carbon budgets for stabilizing global warming. Environ. Res. Lett. 10, 075001 (2015).

39. Grubler, A. et al. A low energy demand scenario for meeting the $1.5^{\circ} \mathrm{C}$ target and sustainable development goals without negative emission technologies. Nat. Energy 3, 515-527 (2018).

40. van Vuuren, D. P. et al. Alternative pathways to the $1.5^{\circ} \mathrm{C}$ target reduce the need for negative emission technologies. Nature Clim. Change $\mathbf{8}$, 391-397 (2018)

41. Wise, $\mathrm{M}$. et al. Implications of limiting $\mathrm{CO}_{2}$ concentrations for land use and energy. Science 324, 1183-1186 (2009).

42. Calvin, K. et al. Trade-offs of different land and bioenergy policies on the path to achieving climate targets. Climatic Change 123, 691-704 (2014).

43. Fujimori, S., Hasegawa, T. \& Oshiro, K. An assessment of the potential of using carbon tax revenue to tackle poverty. Environ. Res. Lett. 15, $114063(2020)$

44. Springmann, M. et al. Mitigation potential and global health impacts from emissions pricing of food commodities. Nat. Clim. Change 7, 69-74 (2017)

45. Stehfest, E. et al. Climate benefits of changing diet. Climatic Change 95, 83-102 (2009).

46. Hasegawa, T., Havlík, P., Frank, S., Palazzo, A. \& Valin, H. Tackling food consumption inequality to fight hunger without pressuring the environment. Nat. Sustain. 2, 826-833 (2019).

47. Leclère, $\mathrm{D}$. et al. Bending the curve of terrestrial biodiversity needs an integrated strategy. Nature 585, 551-556 (2020).

48. Fujimori, S. et al. Macroeconomic impacts of climate change driven by changes in crop yields. Sustainability 10, 3673 (2018).

49. Reilly, J., Hohmann, N. \& Kane, S. Climate change and agricultural trade. Glob. Environ. Change 4, 24-36 (1994).

50. Bodirsky, B. L. et al. Reactive nitrogen requirements to feed the world in 2050 and potential to mitigate nitrogen pollution. Nat. Commun. 5, 3858 (2014)

51. Vitousek, P. M., Menge, D. N. L., Reed, S. C. \& Cleveland, C. C. Biological nitrogen fixation: rates, patterns and ecological controls in terrestrial ecosystems. Philos. Trans. R. Soc. B 368, 20130119 (2013).

52. Hejazi, M. et al. Long-term global water projections using six socioeconomic scenarios in an integrated assessment modeling framework. Technol. Forecast. Soc. Change 81, 205-226 (2014).

53. van Vuuren, D. P. et al. RCP2.6: exploring the possibility to keep global mean temperature increase below $2^{\circ} \mathrm{C}$. Climatic Change 109, 95-116 (2011).

54. Fricko, O. et al. The marker quantification of the Shared Socioeconomic Pathway 2: A middle-of-the-road scenario for the 21st century. Glob. Environ. Change 42, 251 (2017)

55. Debeljak, M. et al. Potential of multi-objective models for risk-based mapping of the resilience characteristics of soils: demonstration at a national level. Soil Use Manag. 25, 66-77 (2009).

56. Bai, Z. G., Dent, D. L., Olsson, L. \& Schaepman, M. E. Global Assessment of Land Degradation and Improvement: 1. Identification by Remote Sensing (ISRIC-World Soil Information, 2008).

57. van Zeist, W.-J. et al. Are scenario projections overly optimistic about future yield progress? Glob. Environ. Change 64, 102120 (2020).

58. Borgonovo, E. Sensitivity analysis with finite changes: an application to modified EOQ models. Eur. J. Oper. Res. 200, 127-138 (2010).

59. Borgonovo, E. A methodology for determining interactions in probabilistic safety assessment models by varying one parameter at a time. Risk Anal. 30 , 385-399 (2010).

60. Marangoni, G. et al. Sensitivity of projected long-term $\mathrm{CO}_{2}$ emissions across the Shared Socioeconomic Pathways. Nat. Clim. Change 7, 113-117 (2017).

61. Fujimori, S., Hasegawa, T., Masui, T. \& Takahashi, K. Land use representation in a global CGE model for long-term simulation: CET vs. logit functions. Food Sec. 6, 685-699 (2014).

62. Fujimori, S., Masui, T. \& Matsuoka, Y. AIM/CGE [Basic] Manual (Center for Social and Environmental Systems Research, National Institute for Environmental Studies, 2012).

63. Woltjer, G. B. \& Kuiper, M. H. The MAGNET Model: Module Description (LEI Wageningen UR, 2014).

64. Stehfest, E., van Vuuren, D., Bouwman, L. \& Kram, T. Integrated Assessment of Global Environmental Change with IMAGE 3.0: Model Description and Policy Applications (PBL Netherlands Environmental Assessment Agency, 2014)

65. Lucas, P. L., van Vuuren, D. P., Olivier, J. G. J. \& den Elzen, M. G. J. Long-term reduction potential of non- $\mathrm{CO}_{2}$ greenhouse gases. Environ. Sci. Policy 10, 85-103 (2007).

66. Havlík, P. et al. Climate change mitigation through livestock system transitions. Proc. Natl Acad. Sci. USA 111, 3709-3714 (2014).

67. Kindermann, G. E., Obersteiner, M., Rametsteiner, E. \& McCallum, I. Predicting the deforestation-trend under different carbon-prices. Carbon Balance Manag. 1, 15 (2006) 
68. Kyle, P. et al. GCAM 3.0 Agriculture and Land Use: Data Sources and Methods (Pacific Northwest National Laboratory, 2011).

69. Calvin, K. et al. GCAM v5.1: representing the linkages between energy, water, land, climate, and economic systems. Geosci. Model Dev. 12, 677-698 (2019).

70. Wise, M. \& Calvin, K. GCAM 3.0 Agriculture and Land Use: Technical Description of Modeling Approach (PNNL, 2011).

71. Armington, S. P. A theory of demand for products distinguished by place of production. Staff Papers 16, 159-178 (1969).

72. Domínguez, I. P. et al. An Economic Assessment of GHG Mitigation Policy Options for EU Agriculture. Report No. JRC101396 (Publications Office of the European Union, 2016).

73. Sands, R. D., Malcolm, S. A., Suttles, S. A. \& Marshall, E. Dedicated Energy Crops and Competition for Agricultural Land (US Department of Agriculture, 2017).

74. Lanz, B. \& Rutherford, T. F. GTAPinGAMS: multiregional and small open economy models. J. Glob. Econ. Anal. 1, 1-77 (2016).

75. The State of Food Insecurity in the World 2012 (FAO, 2012).

76. Emissions Database for Global Atmospheric Research (EDGAR) Version 4.2 (Joint Research Centre, European Commission, 2012); http://edgar.jrc.ec. europa.eu

77. FAO Methodology for the Measurement of Food Deprivation: Updating the Minimum Dietary Energy Requirements (FAO, 2008).

78. Food Security Indicators (FAO, 2013).

79. Energy and Protein Requirements (FAO and World Health Organization, 1973)

80. Shared Socioeconomic Pathways (SSP) Database Version 0.9.3 (International Institute for Applied Systems Analysis, 2012); https://ntcat.iiasa.ac.at/SspDb

\section{Acknowledgements}

S. Fujimori, W.W., T.H. and K.T. are supported by the Environment Research and Technology Development Fund (JPMEERF20202002) of the Environmental Restoration and Conservation Agency of Japan. S. Fujimori, T.H. and K.T. are supported by the Sumitomo Foundation. W.W. was supported by the Japan Society for the Promotion of Science KAKENHI (grant no. JP20K20031). H.v.M., A.T. and W.-J.v.Z. received funding from the Dutch Ministry of Agriculture, Nature and Food Security through the Wageningen University Knowledge Base programme (Circular and Climate Neutral Society, KB-34-003-001 Integrated toolbox for cross-sectoral forward looking assessments and scenarios). S. Frank, P.H. and H.V. received funding from the European Union's H2020 ENGAGE (grant no. 821471) and NAVIGATE (grant no. 821124). This research was supported by the Economic Research Service of the US Department of Agriculture.

\section{Author contributions}

S. Fujimori and W.W. designed the research. W.W. and S. Fujimori carried out analysis of the modelling results. W.W. created figures. S. Fujimori and W.W. wrote the draft of the paper. S. Fujimori, W.W., T.H., J.D., S. Frank, J.H., P.K., R.S., W.-J.v.Z., P.H., I.P.D. A.S., E.S., A.T., H.V. and H.v.M. set up the model. W.W., T.H., J.D., S. Frank, J.H., P.K., R.S. and W.-J.v.Z. simulated the model, and all authors contributed to writing the entire manuscript.

\section{Competing interests}

The authors declare no competing interests. The findings and conclusions in this publication are those of the authors and should not be construed to represent any official USDA or US government determination or European Commission policy.

\section{Additional information}

Supplementary information The online version contains supplementary material available at https://doi.org/10.1038/s43016-022-00464-4.

Correspondence and requests for materials should be addressed to Shinichiro Fujimori or Wenchao Wu.

Peer review information Nature Food thanks Alexandre Köberle and the other anonymous, reviewer(s) for their contribution to the peer review of this work.

Reprints and permissions information is available at www.nature.com/reprints. Publisher's note Springer Nature remains neutral with regard to jurisdictional claims in published maps and institutional affiliations.

(c) The Author(s), under exclusive licence to Springer Nature Limited 2022, corrected publication 2022 


\section{Reporting Summary}

Nature Portfolio wishes to improve the reproducibility of the work that we publish. This form provides structure for consistency and transparency in reporting. For further information on Nature Portfolio policies, see our Editorial Policies and the Editorial Policy Checklist.

\section{Statistics}

For all statistical analyses, confirm that the following items are present in the figure legend, table legend, main text, or Methods section.

$\mathrm{n} / \mathrm{a} \mid$ Confirmed

$\square \bigotimes$ The exact sample size $(n)$ for each experimental group/condition, given as a discrete number and unit of measurement

Х $\square$ A statement on whether measurements were taken from distinct samples or whether the same sample was measured repeatedly

$\square$ The statistical test(s) used AND whether they are one- or two-sided

$\square$ Only common tests should be described solely by name; describe more complex techniques in the Methods section.

Х $\square$ A description of all covariates tested

Х $\square$ A description of any assumptions or corrections, such as tests of normality and adjustment for multiple comparisons

$\checkmark$ A full description of the statistical parameters including central tendency (e.g. means) or other basic estimates (e.g. regression coefficient)

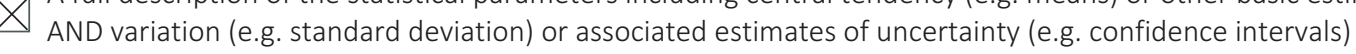

$\square$ For null hypothesis testing, the test statistic (e.g. $F, t, r$ ) with confidence intervals, effect sizes, degrees of freedom and $P$ value noted

Give $P$ values as exact values whenever suitable.

\ $\square$ For Bayesian analysis, information on the choice of priors and Markov chain Monte Carlo settings

\ $\square$ For hierarchical and complex designs, identification of the appropriate level for tests and full reporting of outcomes

\ $\square$ Estimates of effect sizes (e.g. Cohen's $d$, Pearson's $r$ ), indicating how they were calculated

Our web collection on statistics for biologists contains articles on many of the points above.

\section{Software and code}

Policy information about availability of computer code

\section{Data collection GAMS and R}

Data analysis $R$

For manuscripts utilizing custom algorithms or software that are central to the research but not yet described in published literature, software must be made available to editors and reviewers. We strongly encourage code deposition in a community repository (e.g. GitHub). See the Nature Portfolio guidelines for submitting code \& software for further information.

\section{Data}

Policy information about availability of data

All manuscripts must include a data availability statement. This statement should provide the following information, where applicable:

- Accession codes, unique identifiers, or web links for publicly available datasets

- A description of any restrictions on data availability

- For clinical datasets or third party data, please ensure that the statement adheres to our policy

Scenario data is accessible online via the ENGAGE Scenario Database at https://data.ene.iiasa.ac.at/engage/. Data derived from the original scenario database, which is shown as figures but is not in the above database, is available upon reasonable request from the corresponding author. The scenario name mapping table between this paper and the database are shown in Supplementary table 2. 


\section{Field-specific reporting}

Please select the one below that is the best fit for your research. If you are not sure, read the appropriate sections before making your selection.
Life sciences
Behavioural \& social sciences
$\bigotimes$ Ecological, evolutionary \& environmental sciences

For a reference copy of the document with all sections, see nature.com/documents/nr-reporting-summary-flat.pdf

\section{Ecological, evolutionary \& environmental sciences study design}

All studies must disclose on these points even when the disclosure is negative.

$\begin{array}{ll}\text { Study description } & \text { We collect the national future scenarios generated by computer simulation model (integrated assessment model) which include } \\ \text { energy system, economic and land-use information and then made simple statistical analysis. }\end{array}$

Research sample $\quad$ scenarios that are from 6 countries, 7-8 scenarios and multiple years every 5 year steps from 2010 to 2050.

Sampling strategy We collect as much as possible from Asian countries where integrated assessment models and sufficient variable reporting of scenarios are available.

Data collection The corresponding author collects the data from individual national teams.

Timing and spatial scale We collect the scenarios that are generated around April to July in 2020.

Data exclusions No data are excluded.

Reproducibility All data are generated by simulation models which must be able to reproduce.

Randomization There is no randomization

Blinding No blinding

Did the study involve field work? $\square$ Yes $\$ No

\section{Reporting for specific materials, systems and methods}

We require information from authors about some types of materials, experimental systems and methods used in many studies. Here, indicate whether each material, system or method listed is relevant to your study. If you are not sure if a list item applies to your research, read the appropriate section before selecting a response.

\begin{tabular}{|c|c|}
\hline n/a & Involved in the study \\
\hline$\bigotimes$ & $\square$ Antibodies \\
\hline 邓 & Eukaryotic cell lines \\
\hline Х & Palaeontology and archaeology \\
\hline$\bigotimes$ & Animals and other organisms \\
\hline$\bigotimes$ & $\square$ Human research participants \\
\hline$\bigotimes$ & $\square$ Clinical data \\
\hline Х & $\square$ Dual use research of concern \\
\hline
\end{tabular}

\begin{tabular}{l|l}
\multicolumn{2}{l}{ Methods } \\
\hline n/a & Involved in the study \\
$\square$ & $\square$ ChIP-seq \\
$\searrow$ & $\square$ Flow cytometry \\
$\searrow$ & $\square$ MRI-based neuroimaging
\end{tabular}

